\title{
Properties of the surface electromyogram following traumatic spinal cord injury: a scoping review
}

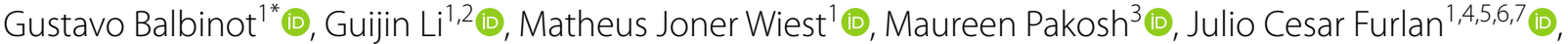 \\ Sukhvinder Kalsi-Ryan ${ }^{1,4,8}$ (D) and Jose Zariffa ${ }^{1,2,4,9}$ (D)
}

\begin{abstract}
Traumatic spinal cord injury (SCI) disrupts spinal and supraspinal pathways, and this process is reflected in changes in surface electromyography (sEMG). sEMG is an informative complement to current clinical testing and can capture the residual motor command in great detail_-including in muscles below the level of injury with seemingly absent motor activities. In this comprehensive review, we sought to describe how the sEMG properties are changed after $\mathrm{SCl}$. We conducted a systematic literature search followed by a narrative review focusing on sEMG analysis techniques and signal properties post-SCI. We found that early reports were mostly focused on the qualitative analysis of sEMG patterns and evolved to semi-quantitative scores and a more detailed amplitude-based quantification. Nonetheless, recent studies are still constrained to an amplitude-based analysis of the SEMG, and there are opportunities to more broadly characterize the time- and frequency-domain properties of the signal as well as to take fuller advantage of high-density EMG techniques. We recommend the incorporation of a broader range of signal properties into the neurophysiological assessment post-SCl and the development of a greater understanding of the relation between these sEMG properties and underlying physiology. Enhanced SEMG analysis could contribute to a more complete description of the effects of $\mathrm{SCl}$ on upper and lower motor neuron function and their interactions, and also assist in understanding the mechanisms of change following neuromodulation or exercise therapy.
\end{abstract}

Keywords: Surface electromyography, Spinal cord injuries, Scoping review, Electrophysiology

\section{Introduction}

Traumatic spinal cord injury (SCI) may lead to severe sensorimotor dysfunction depending on the level and severity of injury. Changes in motor properties include muscle atrophy, muscle fiber type transformation, and increased passive stiffness in muscles and tendons [1], resulting in significant reductions in muscle strength, coordination [2], and functionality [3]. Symptoms of motor impairment are detected clinically by assessing the

\footnotetext{
*Correspondence: gustavo.balbinot@uhn.ca

${ }^{1}$ KITE-Toronto Rehabilitation Institute, University Health Network, Toronto, ON M5G 2A2, Canada
}

Full list of author information is available at the end of the article residual strength, sensibility and/or muscle activation of distinct muscle groups affected by the lesion using, for example, manual muscle testing (MMT). Clinical motor assessments such as the International Standards for Neurological Classification of Spinal Cord Injury (ISNC$\mathrm{SCI}$ ) and the Graded Redefined Assessment of Strength, Sensibility, and Prehension (GRASSP) provide valuable information regarding strength and function [4-6]. This information can be further supplemented by electrophysiological approaches, among which a non-invasive assessment using the surface electromyogram (sEMG) has a number of advantages [7].

sEMG has been suggested to be a good marker for muscle health and function [8]. Importantly, sEMG original author(s) and the source, provide a link to the Creative Commons licence, and indicate if changes were made. The images or other third party material in this article are included in the article's Creative Commons licence, unless indicated otherwise in a credit line to the material. If material is not included in the article's Creative Commons licence and your intended use is not permitted by statutory regulation or exceeds the permitted use, you will need to obtain permission directly from the copyright holder. To view a copy of this licence, visit http://creativecommons.org/licenses/by/4.0/. The Creative Commons Public Domain Dedication waiver (http://creativeco mmons.org/publicdomain/zero/1.0/) applies to the data made available in this article, unless otherwise stated in a credit line to the data. 
amplitude highly correlates with strength and recovery, and can detect muscle activity in patients with no visible movement below the spinal injury level [9-11] (Fig. 1). sEMG assessments are not constrained by ceiling effects, with high variability of sEMG amplitude for example reported in individuals whose muscles were at a given 'ceiling' motor score of 5/5 (using MMT) [12]. Furthermore, sEMG can be beneficial to investigate muscles whose strength is difficult to measure, such as at thoracic levels. sEMG allows us to assess in high resolution the activity of several muscles at the same time during complex motor tasks, including activities of daily living, gait or reaching to grasping movements. It further allows the exploration of neuromuscular properties at rest or under passive movements, the residual control of volitional activity by the motor cortex, and the spontaneous

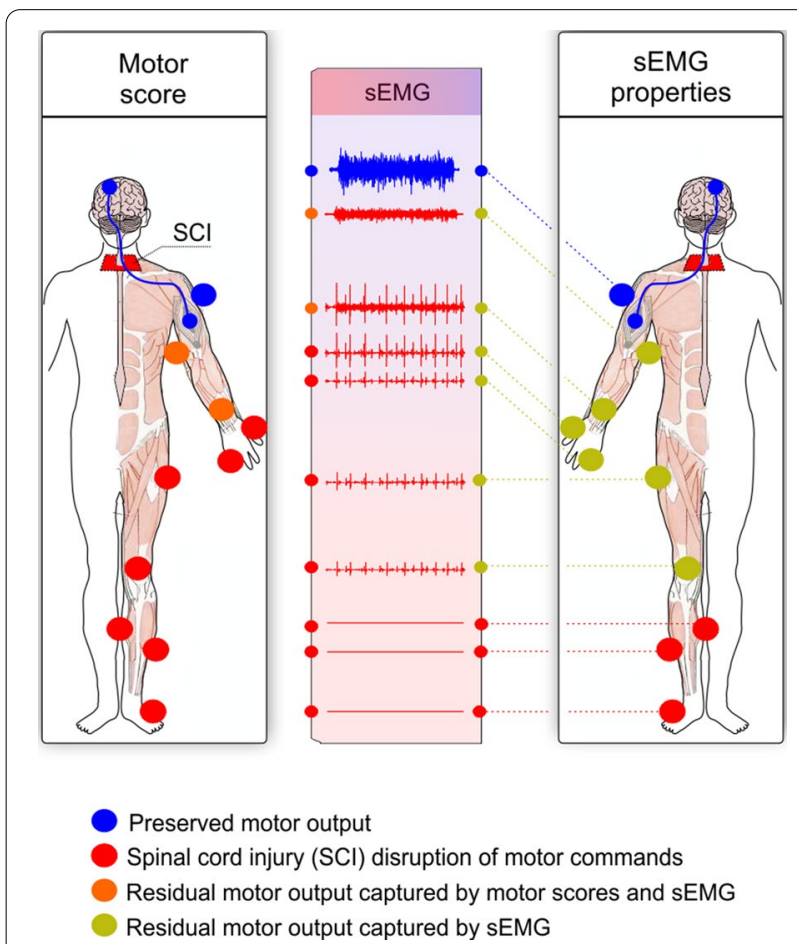

Fig. 1 The surface electromyography (sEMG) is sensitive to detect residual motor commands from muscles with motor scores of zero. Spinal cord injury (SCl, red) disrupts motor commands from the brain (blue), hampering the motor output. The figure shows a hypothetical example using the main muscles assessed in the International Standards for Neurological Classification of Spinal Cord Injury (ISNCSCI). The motor output is commonly measured using motor scores (blue, orange or red dots in the left figure for intact, impaired or absent output, respectively). The sEMG assessment is able to capture the residual motor output in greater detail compared to motor scores because muscles with no motor scores can still display sEMG activity (blue, yellow or red dots in the right-side figure for normal, altered or absent sEMG, respectively). Symmetrical impairment has been assumed for ease of visualization or reflex activity intrinsic to the spinal cord [13]. Given the variety and depth of information that can be obtained from sEMG, an accurate interpretation of the signal properties after $\mathrm{SCI}$ is needed.

In this context, characterizing the impact of the SCI itself on sEMG is of interest for multiple reasons. First, injury-related changes and spontaneous recovery in the sEMG must be understood in order to isolate the impact of interventions. Second, neural interfaces that rely on sEMG require a good understanding of the expected signal properties. Third, a thorough understanding of what information can and cannot be obtained from non-invasive methods is essential to promoting the translation of electrophysiological techniques into routine clinical use. How are the sEMG properties changed after SCI? The answer to this question is not trivial, especially given that the sEMG signal reflects the net output of complex interactions between intrinsic spinal cord circuits, motor axon properties, and muscular mechanisms. sEMG is a wellestablished methodology to explore muscle activity after SCI; however, there is no consensus on data analysis and reporting strategies. The most common reporting methodology utilizes the signal amplitude, typically representing the average or maximal value recorded at a given time or window after some smoothing and normalization steps. However, the raw sEMG signal has the potential to be analyzed and expressed in many ways using temporal, spectral, and spatial techniques. A broad understanding of sEMG changes after SCI is of great interest in order to fully realize the potential of this measurement modality to characterize neurorecovery and support the development of neurorehabilitation technologies [14-16].

This scoping review aims to summarize and critically appraise the existing literature on how SCI can alter the sEMG properties. We distilled the large SCI literature reporting sEMG properties during residual volitional movements or abnormal spontaneous activity. These two domains are clinically significant given that neurorehabilitative interventions after SCI are thought to increase volitional control and reduce spontaneous activity. Accordingly, our results are structured around the different properties of the sEMG that can be expected to change after SCI. Insights into the neurophysiological basis of these phenomena are discussed and a new evidence-based perspective on the use of sEMG after SCI is provided.

\section{Methods}

\section{Registry of Systematic Review Protocol}

This is a scoping review using a systematic search (hybrid review). The systematic search was registered within the International Prospective Register of Systematic Reviews (https://www.crd.york.ac.uk/prospero/\#aboutregpage; 
PROSPERO; Registration number CRD42020159040) and the Open Science Framework (https://osf.io/cg6yu/). Subsequently, a systematic review of the literature was conducted according to the checklist for the Preferred Reporting Items for Systematic reviews and Meta-Analyses extension for Scoping Reviews (PRISMA-ScR) Checklist [17].

\section{Information sources}

Seven electronic databases were searched to avoid a biased literature sample: Medline (Ovid; 1510 entries), Cochrane Central Register of Controlled Trials (116 entries), Cochrane Database of Systematic Reviews (17 entries), Embase (1680 entries), Emcare (555 entries), Cumulative Index to Nursing \& Allied Health Literature (CINAHL; 295 entries), and PubMed (non-Medline; 157 entries). The searches were originally performed on December 23rd, 2019 with no time limitations and rerun on September 22nd, 2020. No limits were applied for language to avoid excluding references not assigned to a language. References were also searched manually by reviewing reference lists of the included studies. Refer to Additional file 1: Table S1 for the Medline search strategy; similar strategies were used for the other six databases.

\section{Eligibility criteria}

To be included, studies had to: (1) report sEMG properties in SCI participants ( $\geq 4 \mathrm{SCI}$ individuals); (2) include participants with traumatic SCI $(>50 \%$ of the total SCI sample); and (3) be written in English. Regarding (1), we defined the sample size threshold a priori to accommodate the low prevalence characteristic of SCI while balancing the need to select studies that contain generalizable information. In (2), despite the obvious differences in the time profile of disease onset in traumatic and non-traumatic (e.g., degenerative cervical myelopathy) SCI, it is thought that both lead to similar white matter degeneration [18]. Further studies are needed to understand the existence of subtle white matter degeneration between these conditions [18]. To the best of our knowledge, there is no evidence of changes in sEMG properties between these conditions. However, we decided to take a conservative approach and excluded articles where most participants were impaired due to a non-traumatic SCI (one article). Conference abstracts were excluded due to the lack of full methods and complete data sets. Theses and dissertations were also excluded because it is unclear whether they were peer-reviewed. Case studies or case reports with less than four participants were excluded because of the low sample size and statistical heterogeneity. Studies on respiratory muscles (e.g., diaphragm), sphincter, pelvic floor, or smooth muscles were not included given that some of these muscles are deep (better assessed using intramuscular EMG), display distinct physiological properties (e.g., smooth muscles), or rely to a large extent on rhythmic rather than volitional movement. Studies exploring intramuscular EMG were excluded. Finally, studies aiming at assessing the effects of treatments or interventions such as pharmacotherapy and neurostimulation were also excluded, as our focus was on understanding the impact of the SCI itself on the sEMG.

\section{Search strategy}

A PICO model (Problem/Patient/Population, Intervention/Indicator, Comparison, and Outcome) was used to build search criteria for the electronic databases. The PICO consisted of Population: "Spinal Cord Injury", Intervention/Identifier: "sEMG", and Outcome of interest: "Muscle/Motor Response". Valid subject headings as appropriate for each database were utilized in the search strategies, as were free-text terms relevant to each topical concept.

\section{Study selection}

Duplicate references were removed manually in addition to using Covidence (Melbourne, Australia) and Mendeley software (Mendeley Inc., New York, NY, USA), and manually. Two authors (GB and GL) independently screened titles and abstracts to determine initial eligibility. Eligible references were included for full-text screening. Conflicts were resolved by a third reviewer (MJW).

\section{Data extraction}

Data extraction from each full-text article was completed by the first author (GB) using a personalized spreadsheet, which was pilot-tested and refined using $5 \%$ of the references that passed the full-text screening. Extracted data included: (1) study identification information (author and year); (2) study design; (3) participant demographics: level of injury, American Spinal Injury Association Impairment Scale (AIS), time post-injury, sex, and age; (4) sample size; (5) the motives for using sEMG; (6) muscles evaluated; (7) sEMG equipment and electrodes; (8) electrodes placement and reliability information; (9) sEMG data analysis and reporting strategy; (10) main sEMG findings: means, standard deviations and $p$ values for relevant outcome measures; (11) measures other than sEMG. If insufficient data were reported, the authors were contacted by email.

\section{sEMG scores}

Following the literature search and selection, a data score was assigned by the first author (GB) as follows to sEMG methodology description was rated as present 
or not using the following criteria: sEMG equipment/ electrode and amplification/filtering description was considered present (yes) if the type and settings of equipment were described in sufficient details (e.g., yes: "surface $\mathrm{Ag} / \mathrm{AgCl}$ electrodes with $2 \mathrm{~cm}$ diameter" or no: "surface electrodes"). Similarly, the electrode placement was considered as present if it was described in sufficient detail (e.g., a description of "electrodes were placed at the T-10 vertebral level, $2 \mathrm{~cm}$ lateral from midline" in contrast to "placed on the muscle belly") or based on established references (e.g., yes: SENIAM recommendations for EMG recording procedures). We also rated the sEMG findings employed in the studies using a 3-point scale: qualitative (0; based on sEMG visuals/graphs), semi-quantitative scores (1; e.g., scale from 0 to 5 ) or quantitative (2).

\section{Results}

\section{Overview}

The PRISMA flowchart is described in Fig. 2. Of 4522 references initially captured in the primary search, 175 references were selected and included in the scoping review. Properties of the sEMG following SCI are described considering volitional effort to reflect supraspinal control of movement or the rest/spontaneous activity to reflect pathologic activation intrinsic to the spinal cord. These two domains are intertwined and dependent on dysfunction patterns of upper motor neuron (UMN) and lower motor neuron (LMN). As such, integrative considerations are discussed throughout.

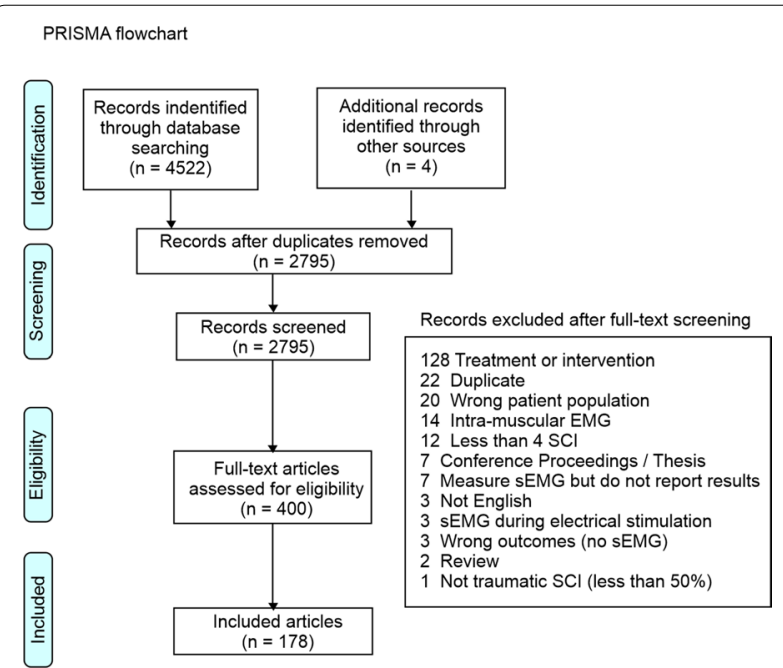

Fig. 2 PRISMA flowchart. PRISMA Preferred Reporting Items for Systematic reviews and Meta-Analyses

\section{Injury and muscle characteristic and participant demographics}

Most of the references identified used the ASIA Impairment Scale (AIS) component of the ISNCSCI to describe their study sample (108 of 178 studies) when measuring sEMG properties at rest (32 studies) or during volitional effort (76 studies). Studies assessing sEMG at rest included more AIS A and B participants $(\approx 71 \%$ of studies), while studies assessing volitional control included mostly AIS C and D ( $\approx 62 \%$ of studies). Most of the studies $(\approx 67 \%)$ were conducted in cervical lesions, indicating sensorimotor impairments in the upper and lower limbs (Fig. 3a, b).

For historical reasons, studies before 1995 did not include AIS information (Fig. 3c). However, some recent work also describes participant injury state only with complete or incomplete or as a mix of gradings, without clear descriptions of impairments.

Many of the studies assessed the properties of sEMG in lower limb muscles ( $\approx 68 \%$ of studies), a substantial amount in upper limbs muscles $(\approx 26 \%$ of studies), and only a few studies in the trunk/head muscles $(\approx 6 \%$ of studies) (Fig. 4a). Tibialis anterior and gastrocnemius were the most studied among lower limb muscles, triceps and biceps brachii among upper limb muscles, and abdominal muscles for the trunk/head (Fig. $4 b-d$ ). Sixty-one percent of the extracted data came from male participants with SCI, 29\% from able-bodied (AB) control participants, and only $13 \%$ from female participants with SCI (Fig. 4e). Seventy-six and 45 studies of 178 did not use an $\mathrm{AB}$ control group or report sex, respectively (Fig. 4f). The average age of SCI participants was 40 years (range 23-69 years; $\mathrm{SD} \pm 7.5$ years; Fig. $4 \mathrm{~g}$ ).

The interest in lower limb muscles, the predominance of males, and lack of $\mathrm{AB}$ control groups (Fig. 4h) can be explained from historical perspectives, but some recent studies are still failing to report sex or gender.

The following sections summarize the currently available evidence about alterations in the characteristics of the sEMG signal after SCI. The focus of these investigations is summarized in Fig. 5.

\section{Properties reflecting volitional control Amplitude-based sEMG during volitional efforts} Using qualitative sEMG graph analysis, early investigations explored the use of volitional muscle activation during postural movements, which described postural patterns and the tendency for clonus of hip flexors/extensors during the act of rising [19], as well as the emergence of abnormal movement synergies following SCI [20, 21].

With the progression of sEMG technology, researchers were able to assess multiple muscle groups 


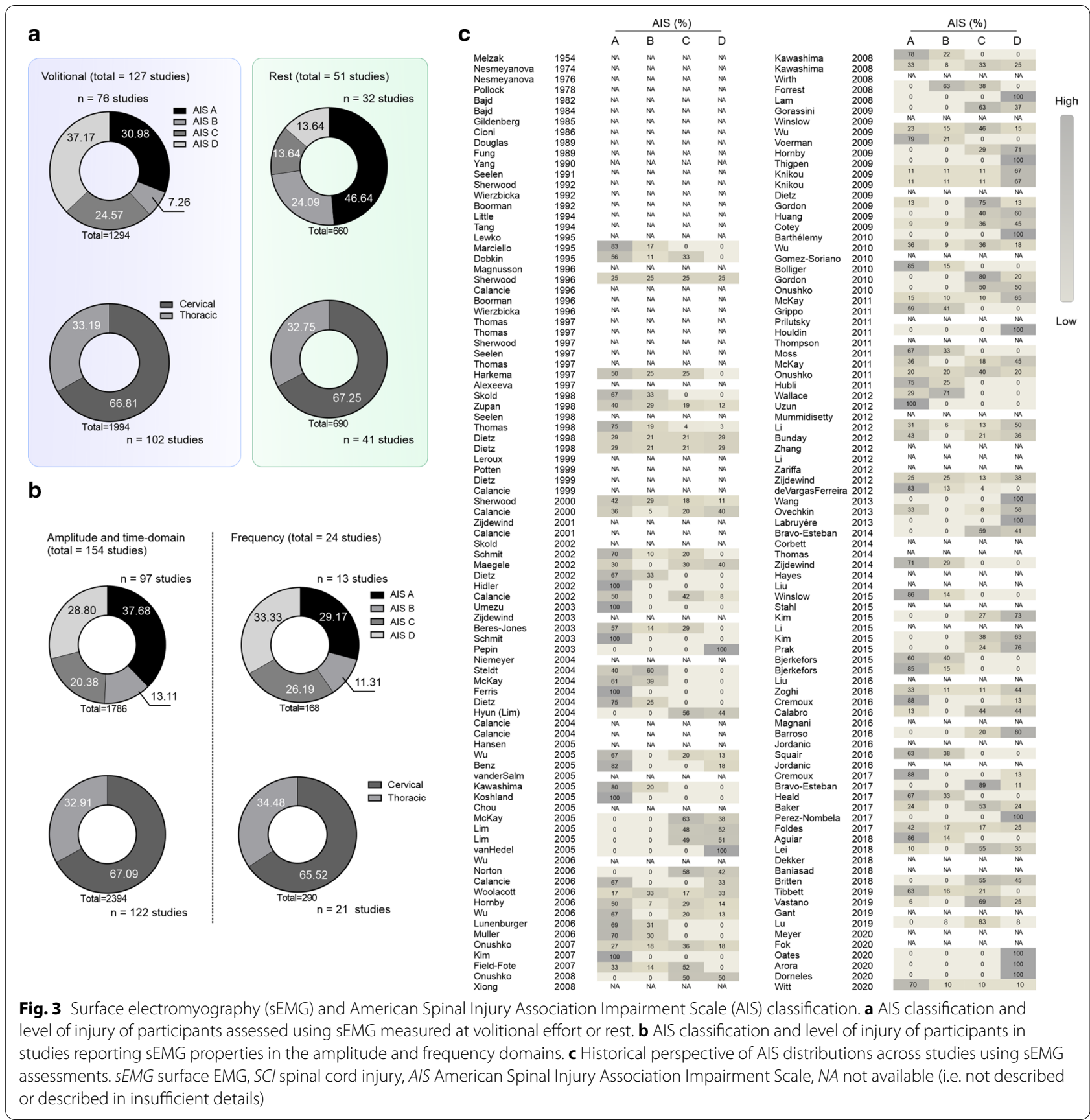

simultaneously with higher resolution. This facilitated the use of sEMG as a means to control assistive devices, as different sites for myoelectric control in individuals with high-level quadriplegia were tested using integrated sEMG amplitude to detect the amount of volitional control over trunk/head muscles [22]. It was evident to these pioneers that sEMG during volitional effort had the ability to detect motor control alterations and was applicable to assistive technology. Nonetheless, some of these early studies employed qualitative assessment of sEMG data (e.g., the amplitude and shape of the sEMG signal) to make inferences about the neurophysiological and functional status of individuals with SCI.

Muscle weakness and spontaneous recovery in acute and sub-acute SCI Of 178 studies, only 18 were conducted during the acute and sub-acute phases of SCI (<1-year post-injury) (Fig. 6a). Muscle weakness, paraly- 


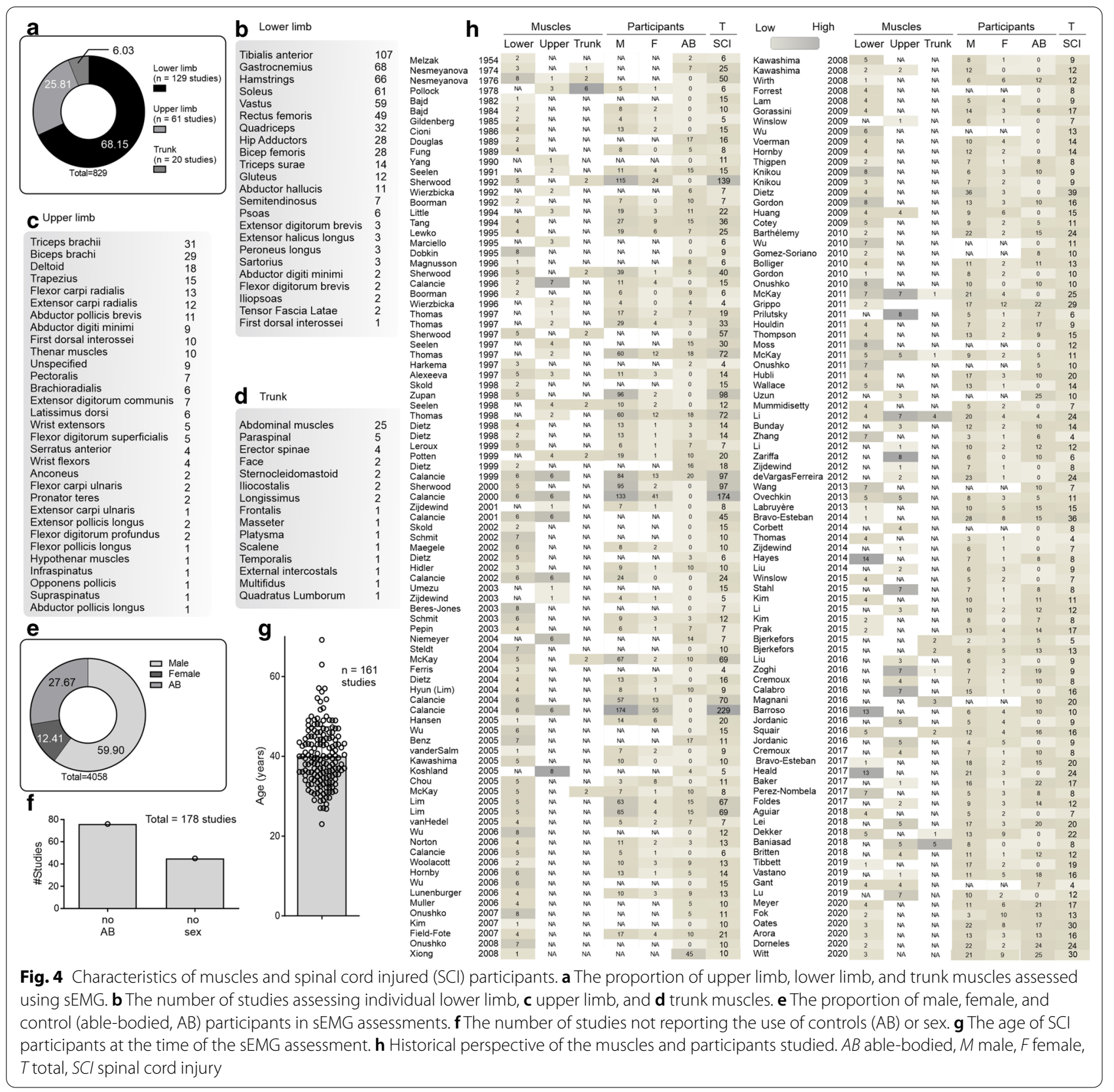

sis, and atrophy were reported following SCI [23, 24]. The mean integrated sEMG generated by individuals with SCI during maximum voluntary contractions (MVCs) were significantly less than those produced by controls, with $71 \%$ of muscles generating less than $10 \%$ of $\mathrm{AB}$ control sEMG [23]. Although individuals with SCI usually produced lower MVC forces, an orderly recruitment of the few units that remain under voluntary control could be demonstrated [25]. Also, in sub-acute SCI, the number of motor units recruited seem to increase with time postinjury-from $40 \pm 33$ to $116 \pm 41$ [26].
The disruption of UMN and LMN activity at specific spinal cord segments results in muscle-specific weakness, which relates to the level of spinal cord lesion and determines muscle activity following SCI [27]. UMN and LMN lesions, mixed weakness, and their dependence on the level of injury were described in detail using sEMG, including amplitude-based properties during voluntary movements [28] and the use of transcranial magnetic stimulation (TMS) [29]. These studies challenged the integrity of the central nervous system using artificial electric or magnetic stimulation in conjunction 


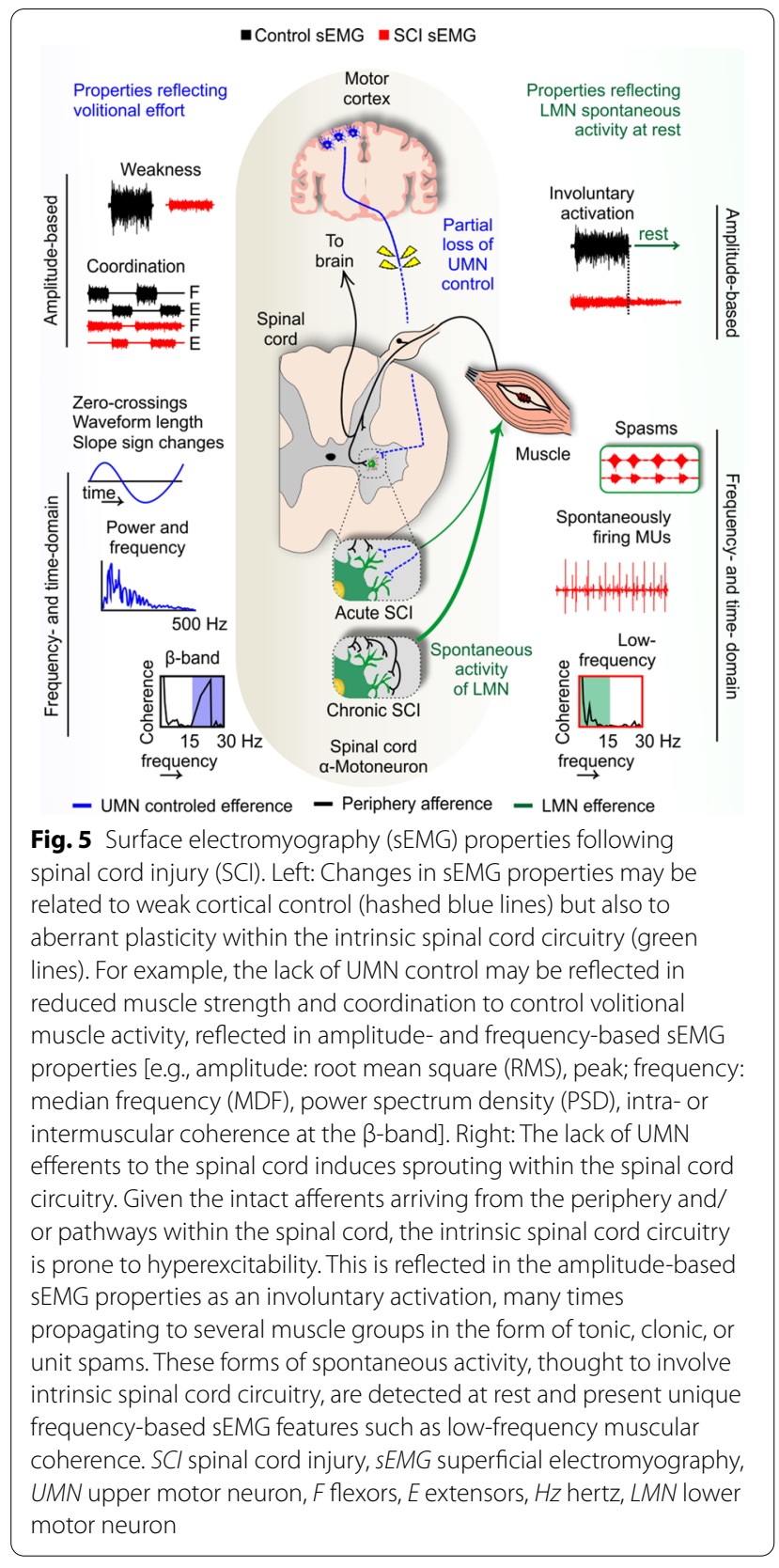

with volitional sEMG measurements. By stimulating the peripheral nerve an $\mathrm{M}$-wave is generated on the muscle and thought to involve the activation of all motor units, regardless of number and size. Thus, the M-wave indicated the maximal recruitment and if divided by the sEMG RMS captured during MVC can indicate the extent of volitional activation of motor units in relation to the maximum (the M/RMS ratio). The M/RMS ratio would be 0 if no $\mathrm{M}$-wave could be produced, indicating LMN lesion, but weak muscles with $\mathrm{M}$-wave amplitudes in the normal range displayed additional sEMG characteristics suggesting UMN dysfunction. For example, muscles with large M/RMS ratio and slow maximum motor unit firing rates (measured using intramuscular EMG) denoted predominant UMN weakness and muscles that showed both very small M-responses and large M/RMS ratios were deemed to represent mixed UMN and LMN impairment [28]. A similar approach using TMS over the motor cortex led to similar findings. Muscles presenting a high semi-quantitative sEMG score at volitional effort also presented greater evoked responses, indicating a relation between residual UMN control and volitional sEMG [29].

The solid relation between muscle strength and sEMG stemmed from the seminal work of Calancie and colleagues and opened new avenues in the application of sEMG in understanding neural plasticity and movement recovery following SCI [30]. These studies showed a consistent relationship between sEMG and muscle force after SCI [11] and the ability to assess the recovery of voluntary movement after acute SCI [10]. Spontaneous recovery of muscle force could be detected in the sEMG signal in great detail and scored using a simple 6-point scale to mimic the ISNCSCI muscle function grading (also from 0 to 5). Utilizing comparable sEMG scores between clinical and sEMG assessments increased the applicability of the sEMG in the clinical settings and the understanding of motor recovery following SCI. This included insights into the distribution and latency of muscle responses to TMS [31], abnormal interlimb responses [32], and the use of the sEMG interference pattern as a biomarker for monitoring lower limb recovery [33]. Most of these studies were performed in large cohorts of participants and provided valuable insights into the mechanisms underlying the restoration of axonal conduction in central motor pathways following SCI.

Dietz and colleagues integrated electrophysiological evaluations into their description of the spontaneous recovery of locomotor muscles over 26 weeks post-injury. sEMG amplitude and reflex activity were absent for up to 14 weeks post-SCI; following resolution of the spinal shock, tendon tap response reappeared, and the sEMG amplitude gradually increased over the next 4 weeksand plateaued at around 22 weeks post-SCI [34, 35]. Further studies confirmed the gradual increase of muscle strength, gait and the motor evoked potentials amplitudes during the first 24 weeks following SCI. During this period, there was a persistent conduction delay within the corticospinal tract but the amplitude of the motor evoked potential increased at a stable level of background sEMG activity of 20\% MVC (unchanged during the first 24 weeks following SCI) [36]. This gain in activation at stable background sEMG activity might indicate improved synchronization of the descending volley 


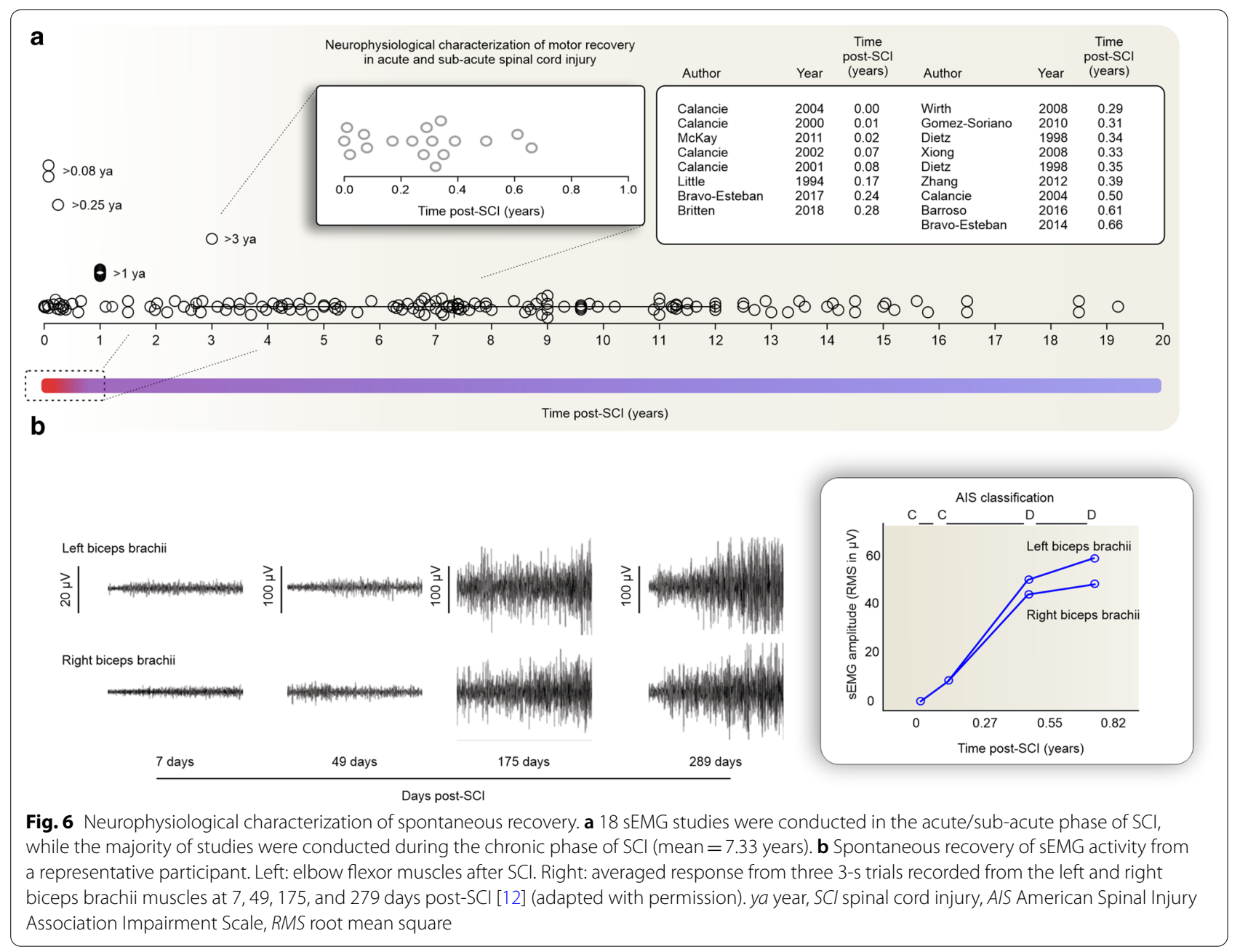

and/or responsiveness of motoneurons to supraspinal input with spontaneous recovery following SCI. In other words, since the corticospinal function did not show significant conduction improvement during motor recovery of acute SCI, it is likely that intrinsic spinal cord plasticity mechanisms play an important role in this process of spontaneous recovery [36]. The heterogeneity of the sEMG response following SCI was highlighted in further studies, and the spontaneous recovery found to be very individualized in terms of sEMG patterns and rate of change over time [37].

Finally, Sherwood and colleagues contributed to the understanding of muscle weakness and recovery following SCI through the introduction of the Brain Motor Control Assessment protocol. This comprehensive multichannel surface sEMG approach allowed a better characterization of motor control features in individuals with UMN dysfunction [38, 39]. The assessment consisted of a battery of tests initially using semi-quantitative features of the sEMG amplitude properties during relaxation (spontaneous firing), reinforcement (amplitude), voluntary movement (amplitude), tonic stretch response, phasic stretch response, presence of clonus, and response to vibration or plantar stimulation [38, 40]. Later, quantitative amplitude measurements of the RMS sEMG were added to this protocol and demonstrated strong between-day reliability [39] and relation to the Ashworth scale [41]. The Brain Motor Control Assessment protocol was further developed by using similarity indices, which compare the sEMG pattern between muscles from $A B$ control and SCI participants [42]. This provided a more detailed description of the spontaneous recovery process $[37,43]$. Spontaneous recovery was described in terms of significant increases in the ability to activate motor units on command, the rate at which those motor units were recruited, and the ability to appropriately organize the motor unit activation across the prime mover, antagonist, and distant muscles [37]. These findings were based on serial recordings made up to 33 weeks post-SCI and showed characteristics of the spontaneous recovery 
process reflected in the sEMG signal (Fig. 6a-inset). In some muscles, at first, only a few motor units fired; however, with recovery, an increase in amplitude was evident accompanied by a progressive decrease in the time from the onset of activity to the peak of activation. In addition to the use of similarity indices, the study by Mckay et al. [37] explored the ability to assess multiple muscle groups using sEMG. This highlighted that spontaneous recovery is not only more activation, but increased activation in the agonists accompanied by reduced co-activation of antagonist or distant muscles. An additional study assessed mixed cohorts of acute and chronic participants and showed the spontaneous recovery process from selected participants (Fig. 6b) [12].

Co-activation in sub-acute SCI was also studied longitudinally using amplitude-based RMS sEMG properties from 3 to 5 months post-SCI. The results suggested an unbalanced recovery of UMN control over muscles (coactivation) and the attenuation of the recovery process by the presence of lower limb hypertonia and involuntary muscle activity [44]. Muscle coordination and sEMG properties at rest will be discussed further in the following sections.

Volitional muscle activation in chronic SCI Early reports of volitional muscle activation during the chronic phase of SCI (>1-year post-injury) aimed at determining the optimal myoelectric control sites [22] and later the neurophysiological characteristics of UMN and LMN lesions [28]. sEMG was also used to investigate the feasibility of using muscles innervated below the injury level as command sources for a neuroprosthesis. The results indicated that although the preservation of a small number of axons alone may not be sufficient to produce functional movement, these signals are likely to be sufficient to control a motor neuroprosthesis [45]. sEMG was also able to capture small differences in well-recovered individuals with incomplete SCI at the chronic phase [46].

The ability of sEMG to capture residual impairments or muscle activity after SCI has been used to categorize muscles according to the presence or absence of detectable movement and determine the extent of preserved muscle activity $[47,48]$, including in abdominal muscles $[49,50]$. Note that in muscles with absent volitional sEMG, an event-related desynchronization was evident when attempting to move, in contrast to SCI muscles with volitional sEMG and AB controls [51].

The Brain Motor Control Assessment introduced in "Muscle weakness and spontaneous recovery in acute and sub-acute SCI" has been applied in a series of studies on volitional control of muscle activity in chronic SCI. The Voluntary Response Index (the volitional component of the Brain Motor Control Assessment) was able to differentiate individuals with $\mathrm{SCI}$ from $\mathrm{AB}$ controls. In addition, the two components of the Voluntary Response Index, magnitude and similarity index, varied independently [52] and were related to preserved corticospinal connections [53]. This technique was also able to distinguish between the most and the least affected sides as well as between AIS D and AIS C individuals [54], and demonstrated good to excellent short- and intermediateterm reliability [55]. In summary, these results validate the sEMG-based Voluntary Response Index as an objective, quantitative, and repeatable laboratory measure of voluntary motor control disruption. The Brain Motor Control Assessment correlated with clinical scale scores acquired more than 48 days after injury; however, such correlations were not found for the first 19 days postinjury [56].

Muscle properties may also change in chronic SCI. The pattern of central motor drive of the plantar flexors indicated that individuals with SCI generated greater activation of the plantar flexors during eccentric MVCs compared with isometric or concentric MVCs, likely related to increased efficacy of muscle spindles Ia- $\alpha$ motoneuron transmission during lengthening contractions $[57,58]$. Finally, the study of voluntary activation of weakened hand intrinsic muscles during sustained contractions indicated that impaired activation due to SCI was more important for explaining weakness compared to muscle atrophy, and greater central fatigue was likely offset by less peripheral fatigue as a result of lower muscle activation [59].

Novel technologies take advantage of high-density sEMG and wearable electrodes. High-density sEMG can provide more detailed information on patterns of muscle activation, which can also be summarized, for example, using the center of gravity $[60,61]$. Wearable technology will soon provide the opportunity to characterize muscular activity under a greater range of sedentary and active conditions in the home environment $[62,63]$.

Motor control and coordination sEMG has been used extensively to gain insights into motor control alterations after SCI. Lines of investigation have included abnormal synergies [20], completion time and accuracy of movements [64, 65], and patterns of co-activation [20, 66, 67]. Another noteworthy application is the study of compensatory movement strategies, which can be accompanied by the development of new muscle synergies [68-72]. Studies have commonly focused on these issues in the context of locomotion [3, 27, 34, 35, 73-98], while fewer studies focused on reach-to-grasp [99-107], and posture and balance [108-112].

While these research efforts have yielded considerable insights into neural control following SCI, most of them 
rely on similar methodologies to quantify the sEMG signal. The emphasis has been placed on timing information to describe patterns of activation, and normalized envelope amplitudes (a summary of the sEMG properties assessed in each study can be found in Table 1). A number of studies have then built on these representations to apply synergy extraction methods that can characterize changes in muscle coordination patterns $[2,103,113-$ 115]. Frequency-based descriptions of the sEMG have also been used in the context of motor control and coordination, and are summarized in the following section.

\section{Time- and frequency-domain characteristics during volitional efforts}

A wide variety of signal processing approaches offer opportunities to describe a recorded signal. The resulting metrics can commonly be categorized as timedomain (i.e., metrics derived from the signal represented as a function of time) or frequency-domain (i.e. metrics derived from the signal transformed into a new representation where at least one axis corresponds to frequency). The amplitude metrics discussed above are time-domain metrics, but are dealt with separately in this article because of their widespread use. Other time-domain sEMG properties have been extensively used in the myoelectric control literature, and are thought to provide indirect information on motor unit activation [116, 117]. Common examples include mean absolute value, variance, zero crossings, slope sign changes, waveform length, and Willison amplitude. The mean absolute value is the mean absolute value of signal $x(t)$ in an analysis time window with $\mathrm{N}$ samples. Zero crossings is the number of times signal $x(t)$ crosses zero within an analysis window. Slope sign change is related to signal frequency and is defined as the number of times that the slope of the EMG waveform changes sign within an analysis window. Willison amplitude is defined as the number of times that the change in EMG signal amplitude exceeds a threshold; it is an indicator of the firing of motor unit action potentials [116]. Frequency-domain sEMG properties are often associated with central fatigue mechanisms [118-120], but also motor unit activation and brain- or spinal cordgenerated rhythms [13, 121-123].

Time-domain features during volitional effort Only a few studies employed these analyses in SCI-related studies. Some studies performed detailed time-domainbased feature extraction to optimize myoelectric pattern recognition-based control systems, using, for example, the mean absolute value, zero crossings, waveform length, slope sign changes, and fourth-order autoregressive coefficients [124-126]. While the high accuracies achieved reinforce that substantial motor control com- mands can be extracted from partially paralyzed muscles using time-domain features after SCI, this type of study design provides limited insight into the effect of $\mathrm{SCI}$ on the sEMG properties. Another time-domain feature, the sample entropy, was also used to develop an algorithm to detect volitional effort onset in SCI, especially due to the spontaneous firing of motor units at rest that contaminates the sEMG signal [127-129].

Frequency-domain characteristics and firing frequency during volitional efforts SCI decreases the motor unit firing during volitional drive. During maximal voluntary effort of the hand thenar muscles, the maximal motor unit firing rate of SCI participants was found to be roughly $15 \mathrm{~Hz}$, much lower compared with $34 \mathrm{~Hz}$ in non-injured participants [130,131]. Although the motor unit activities are reflected in the sEMG signals (using specific electrode configurations-further described in "Amplitude-based sEMG during volitional efforts" section) [132], the motor unit firing rate is often quantified using intramuscular EMG, which is beyond the scope of this review [131]. We focus here on studies analyzing power and frequency of volitional effort using sEMG only.

Changes in sEMG frequency-domain patterns have been associated with improvements in walking; for example, after training, the amount of power in the 7- to 9-Hz clonus band decreased [133]. Variations in muscle activation across gait phases during walking after SCI have been demonstrated using a frequency domain representation based on the Fast Fourier Transform (FFT) [77]. Similarly, wavelet analysis can characterize the time-frequency profile of the sEMG signal with good resolution and contribute to the understanding of targeted walking and corticospinal integrity. Using such techniques, it was shown that an increase of relative semitendinosus intensity in the $38-\mathrm{Hz}$ band during the swing phase was related to targeted walking in SCI, likely reflecting greater corticospinal control before heel-strike during targeted walking [134].

Finally, reduction in mean and median frequencies is a common indicator of increasing levels of muscle fatigue. This reflects that the mechanisms of central fatigue are likely related to the reduced firing of motor units. Early studies in SCI populations took advantage of these properties to test fatigability during wheelchair propulsion and showed how elite wheelchair athletes displayed improved endurance and a slower decline in these frequency-based sEMG properties [118]. Similarly, compared to non-athletes with SCI, individuals with SCI who played wheelchair basketball displayed reduced fatigue [120]. Further studies also reported that spectral analysis of sEMG has been useful clinically 


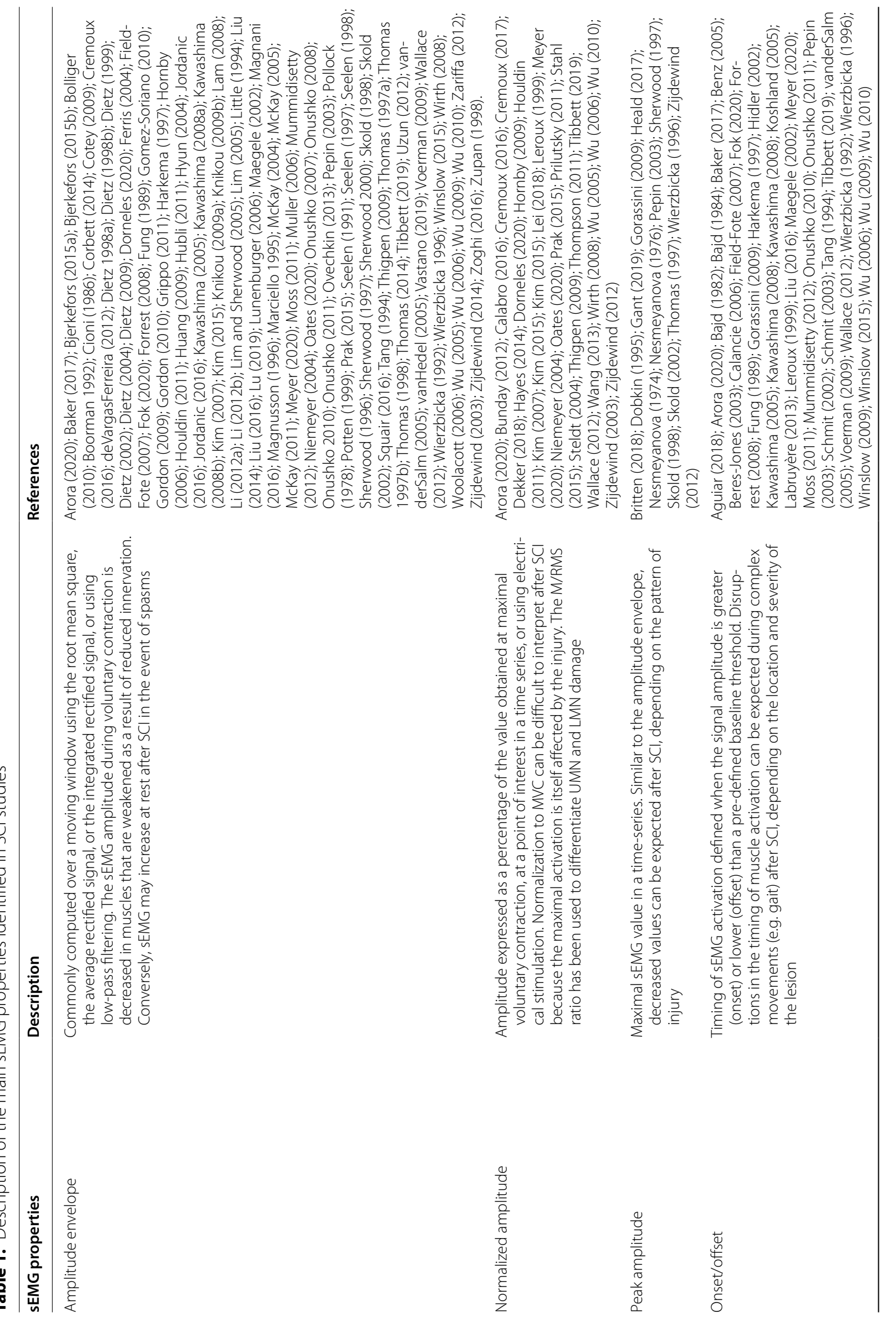




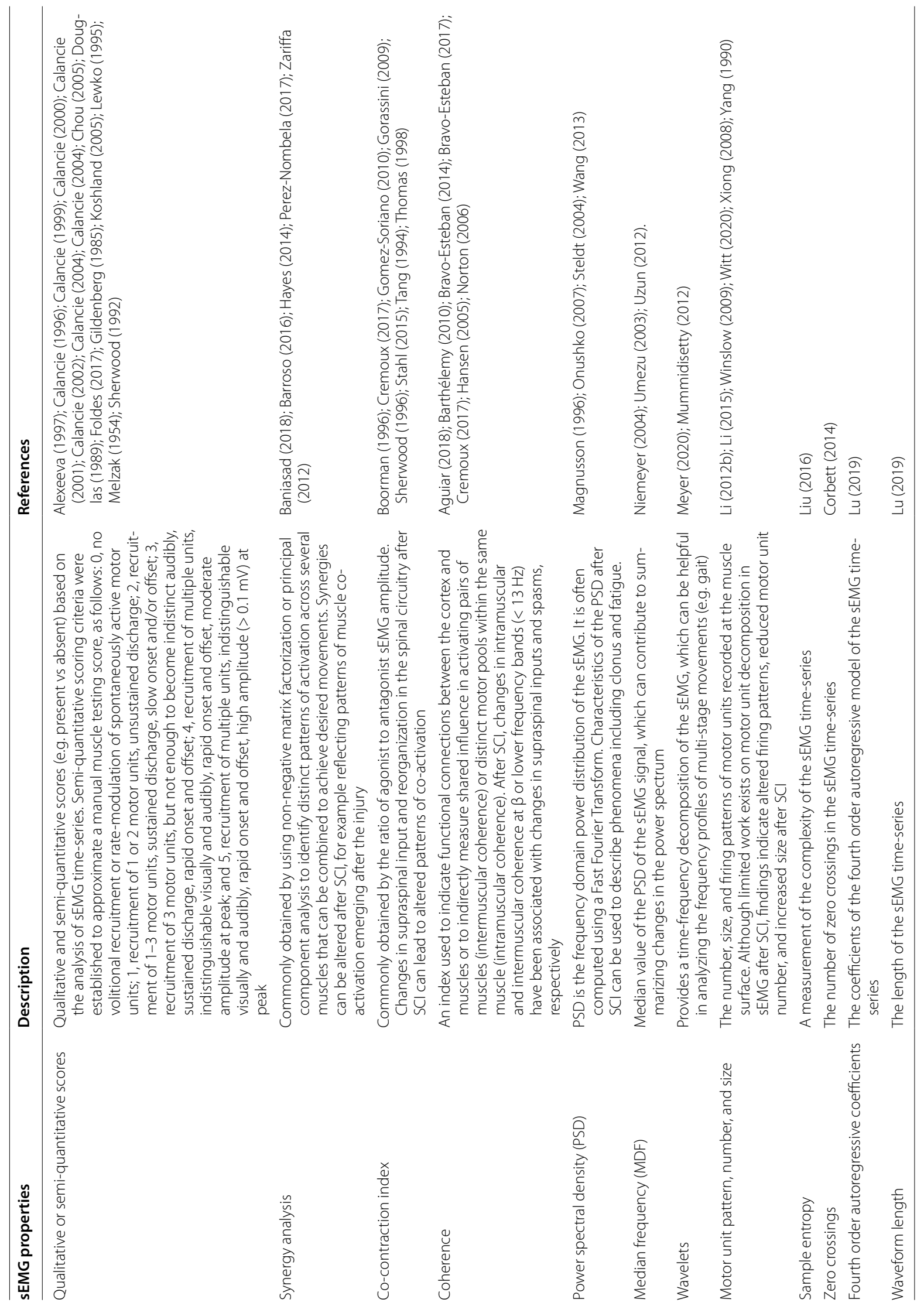


to detect muscle fatigue in the context of assistive technology use [119].

$\beta$-band muscle coherence $\beta$-band activation in cortical motor networks leads to cortical UMN commands often being synchronized within this frequency. As such, $\beta$-band frequency is evident in the sEMG properties of intra- and intermuscular coherence.

Norton and Gorassini have shown that changes in cortically related intermuscular coherence are associated with improvements in locomotor skills following treadmill training, likely mediated by increases in the corticospinal drive to muscles [135]. Intramuscular coherence studies indicated that the main characteristics of coupling between tibialis anterior motor unit activity is in the swing phase of $\mathrm{AB}$ controls (i.e., peaks of coherence around $10-20 \mathrm{~Hz}$ ), but are absent or greatly reduced in SCI participants [136]. Interestingly, SCI participants who display foot drop also showed reduced or absent intramuscular coherence of the foot dorsiflexors during walking [137]. Dorsiflexor intramuscular coherence during volitional effort appears to be related to muscle strength and gait function, and may constitute a measure of muscle strength, gait, and spasticity [121], with the ability to indicate longitudinal adaptive and maladaptive motor control mechanisms [138].

Frequency-based sEMG analysis may also be used to investigate corticomuscular coherence following SCI using electroencephalography. Corticomuscular coherence at lower frequencies $(\approx 10 \mathrm{~Hz})$ may indicate decreased cortical influence on spinal centers, leading to increased muscle co-activation [123]. Interestingly, spasticity was also associated with lower dorsiflexor intramuscular coherence in the $15-30 \mathrm{~Hz}$ band during volitional effort, suggesting that lower coherence is associated with the spontaneous firing of LMN [138]. This will be discussed further in "Time- and frequencydomain characteristics at rest" section.

\section{Properties reflecting LMN spontaneous activity}

SCI reduces the UMN input to the spinal cord circuitry and creates an opportunity for plasticity and reorganization. Synaptic territory may be invaded by preserved connections not interrupted by the SCI, afferents arriving from the periphery (e.g., mechanoreceptors and proprioceptors), and/or pathways within the intrinsic spinal cord circuitry. As a consequence, the temporal and spatial summations of action potentials become unbalanced in the intrinsic spinal cord circuitry and more prone to excitation from the periphery, alongside the reduction of cortical inhibition. This leads to the emergence of hyperreflexia and long-lasting spontaneous firing of LMNs, and also suggests the loss of inhibitory interneurons within the spinal cord circuitry [139]. Amplitude-based sEMG properties can capture the occurrence of this involuntary activity at rest, namely muscle spasms. Muscle spasms are often characterized as unit, clonus, or tonic spasms. In this section, we summarize the available evidence on how the sEMG signal can reflect spontaneous firing in the LMN.

\section{Amplitude-based sEMG at rest}

Harnessing the residual brain influence on spinal cord function includes increasing volitional activation but also reducing involuntary spontaneous activity. sEMG activity below the lesion can be studied in great detail using sEMG amplitude-based properties at rest. For example, similar to volitional contractions but tailored to quantify the response of paralyzed muscles to tendon taps, vibration, and plantar stimulation, the Brain Motor Control Assessment score can reflect the presence or absence of reflexes or the ability of voluntary suppression [40]. The results indicated that $84 \%$ of SCI participants with clinically motor complete SCI were able to demonstrate at least one of the defining features of residual, subclinical brain influence, and could be categorized as 'discomplete' SCI [40]. Data also support the Brain Motor Control Assessment as highly comparable between sessions when patients are stable [39], indicating the possibility of conducting extensive assessments throughout the recovery process. The Brain Motor Control Assessment was also applied to the upper limbs of SCI participants and a significant level of involuntary muscle activity at rest was found compared to $\mathrm{AB}$ control participants. These involuntary activations reduced over time (from $\approx 86$ to $\approx 500$ days post-SCI) and became similar to $\mathrm{AB}$ control participants [43].

Early reports of involuntary sEMG activity in SCI described how the deprivation of supraspinal control leads to an increase in LMN activities. This was manifested in sEMG response induced by passive knee movements, as sinusoidal torques can occasionally induced phasic sEMG and spasms in individuals with SCI [140]. The existence of these abnormal responses was further investigated by testing and modelling spasticity [141, 142]. Later it was demonstrated that voluntary supraspinal suppression of spinal reflex activity was possible for some SCI participants [143, 144]. Following these initial studies of reflex activity, later studies provided more information on how mechanoreceptors, proprioceptors, and the intrinsic spinal cord circuitry mediate the spontaneous activity of LMN and hyperreflexia [98, 145-151] (refer to Additional file 1: Figure S1 for a summary of additional instrumentation used in the studies reviewed).

Reflex responses in the presence of patterned stimuli including rhythmic movements and vibrations have been 
investigated on multiple occasions [91, 93, 96, 131, 149, 152-162]. These investigations have described relationships between spastic reflexes, afferent input patterns and multi-joint responses, and provided insights into the underlying neural circuitry.

Some motor units may show prolonged, contractioninduced firing after the voluntary contraction. This induced motor unit firing may last for minutes-also denominated as unit spasms [130]. The examination of the recruitment, firing rate modulation, and de-recruitment of motor units that underlie spasms of thenar muscles in SCI indicated that mean SEMG and force were strongly associated during the spasms and that some motor units were not de-recruited following spasms but rather continued to fire for several minutes at low firing rates [163]. sEMG provides objective measurements of naturally occurring spasms in contrast to the selfreported spasm counts, which are often used to make clinical decisions, but the former usually involves visual inspection of long sEMG recording [164]. The automatic identification of spasmodic events in long-term sEMG recordings enabled further understanding of these phenomena $[165,166]$. It is feasible to detect spasms since they typically involve a rapid rise in sEMG amplitude followed by a more gradual fall, which is also observed in torque. Interestingly, it was later shown that individuals with SCI may adaptively use spasms to increase force production [131].

Multiple types of sEMG analyses were used to link muscle activity and spasticity measured through the Ashworth scale. Some positive correlations were found by linking sEMG amplitude-based and timing properties, e.g. mean, peak, and the time between onset and peak of electrical activity [167]; predicting the level of spasticity using sEMG features (i.e., RMS of five muscles under two maneuvers) and machine learning algorithms [168]; and, using amplitude-based sEMG data from the Brain Motor Control Assessment [41] and the spinal cord assessment tool for spastic reflexes [169]. The assessment of spasticity using full range passive movements indicated sEMG RMS increased with increasing stretch velocities, providing an objective outcome [170].

Subsequent studies reported weak correlations between the Ashworth scores and reflex activity, and a unique reflex mechanism in SCI was proposed [171]. Similarly, there was a weak association between longterm sEMG recordings (i.e. number and duration of burst) during ADLs and self-reported level of spasticity [172]. The subjective component and lack of reliability in reporting spasticity using the Ashworth scale have been pinpointed as a possible confounding factor in establishing a clear relation between sEMG properties and spasticity [173]. However, the use of sEMG activity was recommended to investigate reflex hyperexcitability and to determine the occurrence of muscle spasms [173]. For example, sEMG measurements of involuntary activity in the lower extremity were not significantly related to perceived impact of spasticity on daily life, although spasm duration was positively associated with clinical extensor spasticity [174]. These studies suggest that the quantification of sEMG during involuntary contractions is important to better understand the relation between neurophysiological and self-reported measures of spasticity. A possible explanation to these contradictory findings and recommendations may lie in the fact that individuals with SCI describe spasticity in terms of their spasms and tone. Thus, multiple tests may be necessary to fully capture both the biological basis and functional impact of spasticity [175].

\section{Time- and frequency-domain characteristics at rest}

Studies on the time-domain SEMG properties at rest are lacking in $\mathrm{SCI}$, which is understandable since timedomain features were first proposed for the active myoelectric control of upper-extremity prosthetic devices $[116,117]$.

Frequency-domain sEMG properties are highly susceptible to noise given the low signal power in sEMG recordings at rest. For example, the investigation of sEMG activity during passive static stretch showed characteristics of "white noise" in the power density spectrums at rest with a median frequency of $400-548 \mathrm{~Hz}$ (AB controls) and $478-540 \mathrm{~Hz}(\mathrm{SCI})$ without a characteristic concentration of frequencies in the spectrum, and with strikingly low power [176].

Frequency-domain characteristics and firing frequency of spontaneous motor unit firing sEMG analysis at rest may provide information on the rate of involuntary motor unit firing and on whether medications can dampen such activity. Few methods have been proposed to identify spontaneous motor unit firing in SCI using sEMG. An automated multi-step classification algorithm of sEMG from paralyzed thenar muscles enabled the detection and classification of spontaneously firing motor units using sEMG [132]. The motor unit number index, another method for estimating the motor unit size and number, was also shown to capture the difference between intact muscles and those paralyzed in SCI-reduced number and greater size of motor units in SCI [26, 177-180]. The main difference between these two methods is the use of a specific configuration of surface electrodes [132], in contrast to the use of standard bipolar surface electrodes configuration (but with the addition of a normalization step using electrical stimulation) [177]. Despite the important applicability in SCI, these methodologies were 
not broadly employed, and as mentioned earlier, most of the studies included in this scoping review assess firing rates using a combination of sEMG and intramuscular EMG (similar to "Frequency-Domain Characteristics and Firing Frequency During Volitional Efforts" Frequency domain and firing frequency during volitional efforts). For instance, the seminal work of Thomas, Zijdewind, and colleagues broadly used the above-mentioned combined approach to understand motor control of the hand thenar muscles in SCI [181].

The involuntary recruitment of populations of motor units during clonus has been described in detail in SCI. It was shown that the clonus frequency ranged from 4.7 to $7.0 \mathrm{~Hz}$ and the firing of motor units seemed to follow orderly recruitment during these involuntary contractions. This pattern of recruitment is consistent with motor unit recruitment seen during many voluntary contractions, and suggests the importance of spinal mechanisms in the control of motor unit behavior in SCI [182]. Another nuance of spontaneous motor unit firing in the hand is the regularity of firing observed in some motor units. Regularly firing motor units seem to be more excitable as they displayed longer after hyperpolarization potentials and higher mean firing rates, likely reflecting active properties (such as persistent currents) within motoneurons. This activity is seen in the absence of voluntary drive but also may underlie the firing patterns typically recorded during voluntary contractions [183]. Indeed, it was shown that coactive motoneurons are likely driven by synaptic inputs from different sources during muscle spasms [163].

Low-frequency muscle coherence In contrast to the $\beta$-band synchronization of UMN signals to the spinal cord, the intrinsic spinal cord circuitry is thought to operate at lower frequencies. Lower frequency oscillation seems to be associated with spasticity during volitional contractions [138] but also with spasms [13]. The recording of sEMG during a 24-h period using a wearable device allowed the detection of natural spasms and the calculation of intermuscular coherence in a set of lower limb muscles. Intermuscular coherence during the spasms occurred at low frequencies (between 2 and $13 \mathrm{~Hz}$ ) in complete SCI, but at higher frequencies in incomplete SCI. The current evidence suggests that the most likely source for this lowfrequency coherence is the spinal cord and its peripheral feedback loops, given the different responses depending on the lesion profile [13].

\section{Discussion}

This scoping review aimed to examine the properties of the sEMG following SCI. Given the increasing role of technology and the possibility to assess neurorecovery in more detail, this review aims to support the interpretation of sEMG signals after SCI, facilitate the choice of sEMG methodology for planning and conducting research in SCI, support the development of assistive technologies, as well as highlight gaps in knowledge.

Among the identified body of evidence, the minority of studies included sEMG measurements beyond amplitude-based analysis. Most studies employed amplitudebased analysis using RMS (57 studies), normalized sEMG (e.g. \%EMG, \%MVC, and \%peak; 33 studies), and qualitative or semi-quantitative scores of the sEMG pattern (16 studies). In contrast, only 19 studies used time-domain or frequency-domain analysis (Table 1). The summarized findings from this review suggest that amplitude-based analysis is effective in indicating muscle strength and recovery following $\mathrm{SCI}$, including important aspects of multi-muscle coordination. Despite these positive findings, time- and frequency-domain analysis may describe the sEMG properties in ways that are not possible with amplitude-based analysis alone, providing a more detailed description of the neurophysiological changes following SCI. Time- and frequency-domain sEMG properties are thought to reflect the motor unit firing patterns, either spontaneous or cortically driven, but more studies are needed to consolidate the relation of these sEMG properties with physiological events. Ultimately, sEMG signals may be better characterized if a broader range of properties is considered.

An important methodological consideration when dealing with amplitude-based sEMG properties is their susceptibility to inter-day and inter-subject variability due to variations in factors including electrode locations and skin impedance. Although normalization (e.g., to MVC) is widely used to attempt to compensate for these issues, a limitation of most sEMG studies in SCI was the lack of reported electrode placement and between-days reliability of the sEMG measurements. Only 51/178 references reported detailed information about electrode placement, but the majority reported details about the sEMG equipment or filtering/amplification procedures (Fig. 7); and $57 \%$ of studies used an $\mathrm{AB}$ control group. Although the use of an uninjured control group depends on the research question, appropriate experimental controls are highly necessary to deal with the stochastic and variable nature of the sEMG signal after SCI. Finally, the well-powered studies from Calancie and Sherwood in the 90's and 2000's are notable but employed mostly semiquantitative sEMG analysis [10, 30, 31, 40, 41, 168].

Another consideration is the relatively small number of studies combining intramuscular EMG and sEMG methodologies. Simultaneous recordings using the two techniques have the potential to improve our understanding of how motor unit firing patterns are reflected in the 


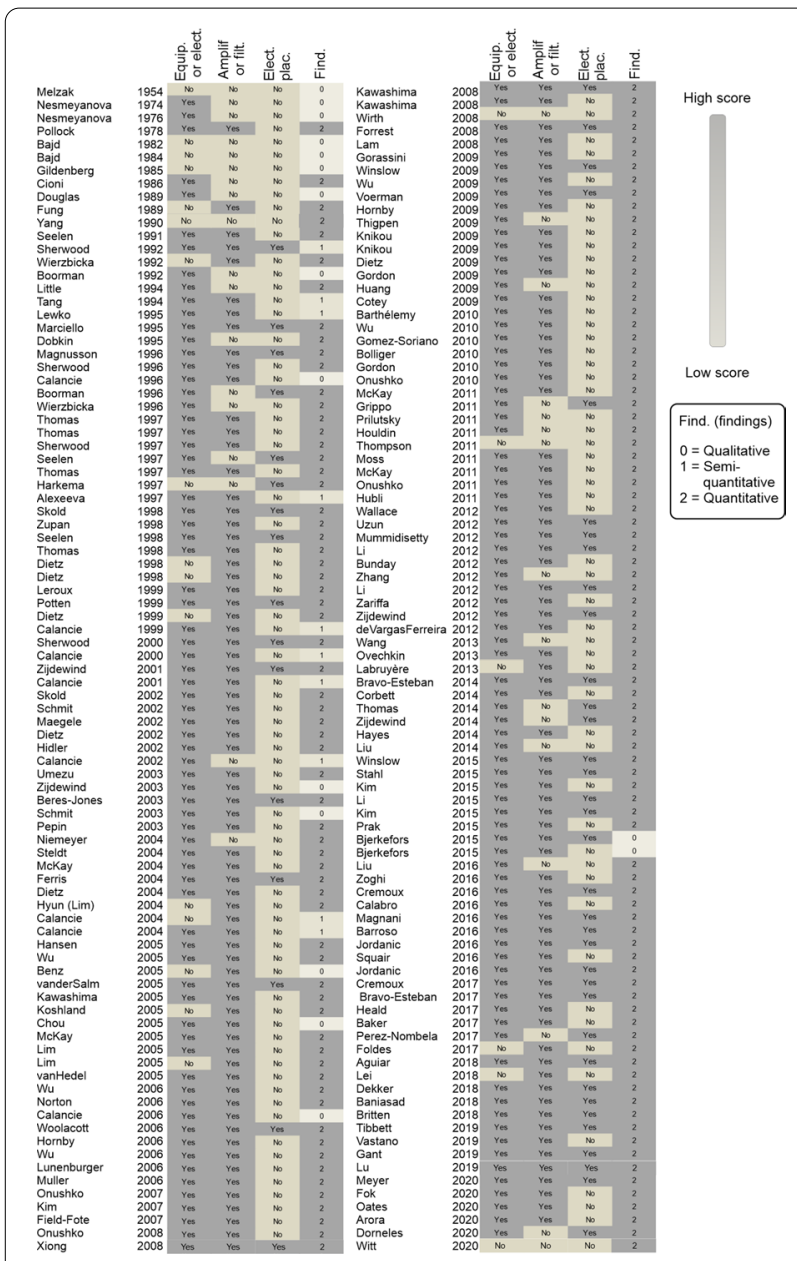

Fig. 7 Description of the surface electromyography (sEMG) methodology. The presence or absence of the description of the sEMG equipment or electrodes, the amplification or filtering procedures, the detailed placement of electrodes (or proper citations) and the type of findings (qualitative: based on visual sEMG graph analysis; semi-quantitative: based on scores of the sEMG pattern; quantitative). Equip. sEMG equipment, Elect. sEMG electrode, Filt. sEMG hardware or digital filtering, Plac. electrode placement on muscles, Find. sEMG outcomes, FFT Fast Fourier transform, PSD Power Spectral Density, MDF median frequency, RMS root mean square

sEMG. The importance of this scoping review is supported by a recent systematic review on the electrophysiological outcome measures in SCI clinical trials, which indicated 27/64 of clinical trials used sEMG analysis and only 1/64 used intramuscular EMG [184]. It is reasonable to view sEMG as the primary choice of neurophysiological method in SCI clinical trials, given its non-invasiveness and ease-of-use. Recent improvements in motor unit decomposition from sEMG offer an exciting opportunity to directly measure motor unit firing rates and obtain greater neurophysiological insights without the need for invasive measurements $[185,186]$. However, these methods require specialized instrumentation, and their use in SCI research has been limited to date.

A broader perspective on the sEMG signal characteristics has the potential to lead to new outcome measures for use in clinical trials, and to benefit the field through the knowledge gained in understanding the relation of these properties with physiology. Most of the studies exploring time- and frequency-domain sEMG properties in detail are conducted in non-injured subjects, other populations (e.g. amputees), or with an insufficient number of SCI participants (less than $4 \mathrm{SCI}$ ) to be included in this scoping review. On the other hand, the SCI studies with larger samples mostly rely only on amplitude-based analysis. This creates an inverse relationship between the sample size and the variety of sEMG properties reported (e.g., properties beyond the amplitude).

In the new era of machine learning, the characterization of the volitional sEMG activity below the lesion has a potential application as a screening tool in the clinical settings [14, 187]. Advancement in technology may promote the development of novel devices with increased portability and ease-of-use. Clinicians may use these sEMG tools during neurorehabilitation, with potential implications to diagnosis and to the optimization of treatment time. Additional characterization of sEMG after SCI may also support the development of assistive technologies such as myoelectric control interfaces [22, $117,124]$.

\section{Implications for clinical practice}

The utility of sEMG is widely appreciated as it is seen to provide simple and easy-to-use assessments of motor impairments and rehabilitation after SCI. On the other hand, as recently described by Pilkar et al. and Merletti et al., there is a range of factors to consider when implementing sEMG assessments in clinical practice [188, 189]. For instance, sEMG requires dedicated resources and infrastructure for equipment, training, and maintenance. Health professionals will need specialized training, ongoing support, and easy-to-use sEMG interfaces [189]. In this context, this scoping review has identified a body of consistent evidence indicating that sEMG is an informative complement to current clinical testing (e.g., MMT), but likely not being fully utilized in terms of the information that it can provide. Looking forward, engineers and software developers must develop sEMG systems that make a wider range of metrics available at the point of care, not restricted to amplitude-based calculations. For example, if easy-to-use sEMG information is available preoperatively, it may avoid common pitfalls in selecting potential donor and recipient muscles when 

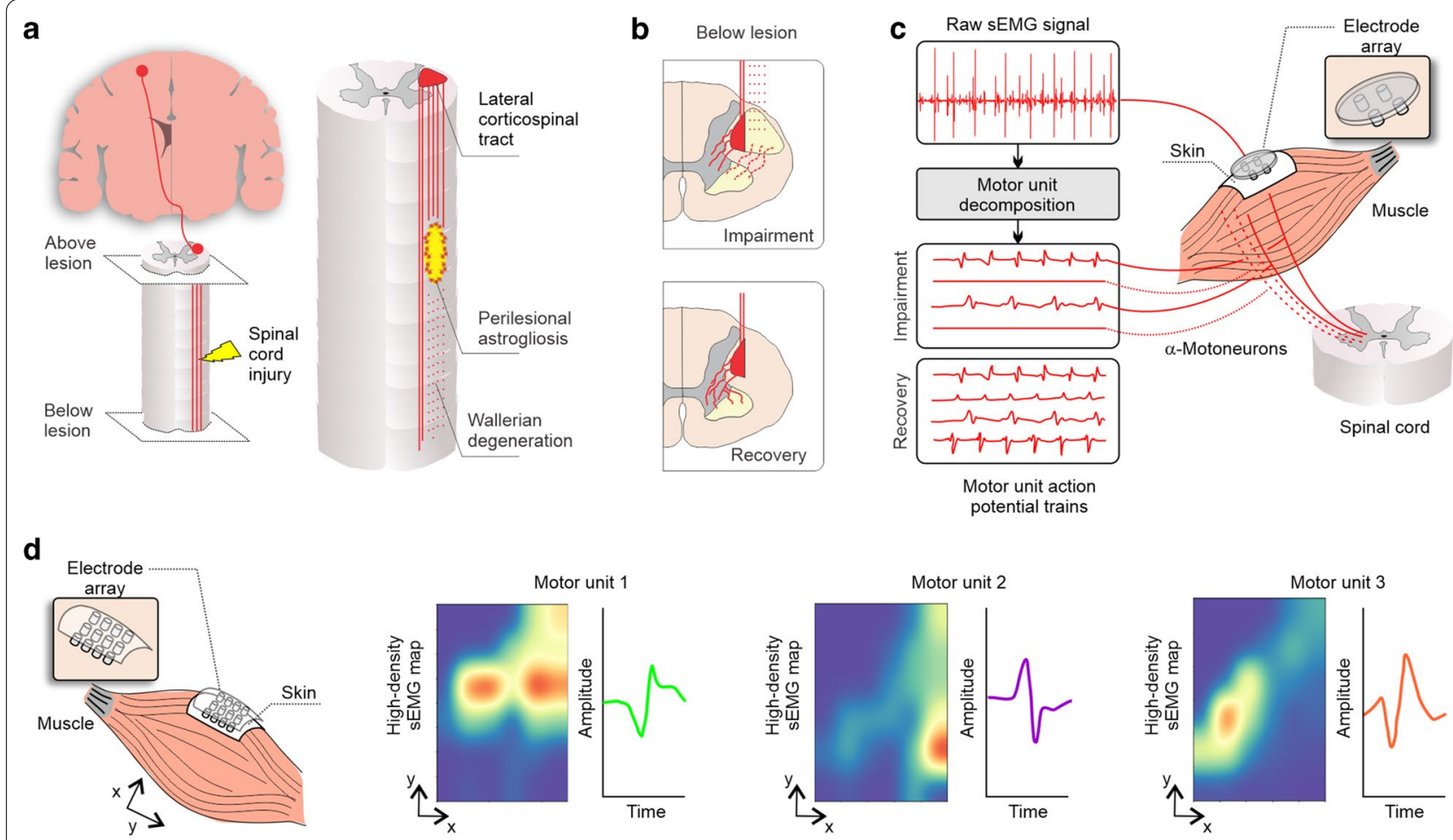

Fig. 8 Overview of conceptual work on high-density SEMG, motor unit decomposition, and its application in SCI. a, left Corticospinal projections (red) and spinal cord injury (yellow). a, right In the intermediate and chronic phases ( 2 weeks to 6 months), axons continue to degenerate and the astroglial scar matures to become a potent inhibitor of regeneration (restrict axonal regrowth and cell migration). The lateral corticospinal tract (red) is the major descending motor tract, which may be damaged after SCl (red hashed lines) [192]. b, upper panel The remaining projections from the corticospinal tract (red solid lines) synapse with a-motoneurons in the spinal cord to control volitional movements-(b, lower panel) which undergo extensive plasticity with motor recovery [193]. c Standard sEMG is able to capture the overall activity of these motor units but four or five small pin electrode arrays are able to decompose the raw sEMG signal into individual motor unit potential trains [186, 194, 195], with potential to track the impairment and recovery of motor unit control after an $\mathrm{SCl}$. The most common techniques used for motor unit decomposition involve the use of the progressive FastlCA peel-off framework [196-198], multichannel blind source separation using convolution kernel compensation [199-201] or specific algorithms, e.g., using machine-learning and time-varying shape discrimination [186, 194, 195]. d The use of multi-electrode arrays increases the spatial resolution; in addition to the motor unit decomposition, multi-electrode arrays can also unveil the territory of each motor unit [202]

attempting surgical nerve transfer to restore upper limb function in SCI [190]. More broadly, a comprehensive understanding of the spontaneous recovery profile in sEMG may provide valuable guidance for therapy selection and progression.

\section{Implications for research}

From a research perspective, the availability of high-quality outcome measures is essential to the successful translation of new interventions. Recent reviews by Hubli et al. and Korupolu et al. have described the use and benefits of electrophysiological outcome measures, including sEMG, in the context of SCI clinical trials [7, 184]. Remaining avenues for improvement include greater standardization as well as ease of implementation. Deeper characterization of the sEMG signal can play a role in this context by identifying signal properties that have suitable psychometric properties to be incorporated into outcome assessments, as well as by improving our understanding of how different metrics relate to the underlying physiology. The potential also exists to simplify data collection, if signal processing or machine learning can be used to extract subtle trends from non-invasive data during simple protocols, rather than requiring invasive techniques or complex stimulation protocols. For instance, the adoption of methods to estimate motor unit firing using sEMG should further advance the understanding of sEMG properties in SCI. The present review lays the groundwork towards these goals.

\section{Limitations}

Our study had some limitations concerning the exclusion of studies on treatment or interventions and the lack of studies encompassing recent advances in highdensity sEMG. First, given our interest in how the sEMG 
properties are changed in response to an $\mathrm{SCI}$, it was considered that any intervention or treatment would have the potential to interfere with the signal characteristics. For example, the use of epidural or transcutaneous spinal cord stimulation may generate electrically induced muscle activation that interferes with the understanding of how the sEMG is changed after an SCI. Other types of treatments were identified, such as pharmacological or rehabilitative (e.g., locomotor training, EMG biofeedback). The most common interventions were the use of assistive devices (e.g., robot-assisted training, exoskeletons, wheelchair). Although the review of these studies would be important, they are outside the scope of our present question and we suggest that future reviews should provide guidance on appropriate methods to use sEMG to answer specific research and clinical questions (including interventional trials).

Secondly, our review identified a lack of studies on high-density sEMG and motor unit decomposition in SCI. Studies on high-density sEMG were mostly conducted in $A B$ participants or in individuals with an SCI but with insufficient sample size to be included in the present review. We believe that the identification of this knowledge gap is an important finding of this scoping review and should further well-sampled and comprehensive studies on how these novel techniques can be applied in SCI. Recently, novel methodological advancements in high-density sEMG preprocessing have been proposed to enhance the diagnostic power in individuals with an SCI, which will help to develop a standard sEMG preprocessing pipeline [191]. In Fig. 8, we provide a simplified overview of some of the conceptual work on high-density sEMG and motor unit decomposition and provide our perspective on how the SCI field can take advantage of these techniques.

An additional limitation is the focus here on limb and trunk muscles. The inclusion of respiration and sphincter muscles would warrant further work, as the differences in neural control and muscle properties could be expected to alter the sEMG properties.

\section{Conclusion}

The research on sEMG in SCI over the past seven decades has accumulated abundant evidence about changes in the sEMG properties after the injury. Most of the studies describe muscle weakness, coordination and spontaneous activity using SEMG amplitude properties. It is known that sEMG can capture the residual motor command in great detail, including in muscles below the level of injury with seemingly absent motor activities. Therapies promoting sensorimotor recovery aim at harnessing these residual supraspinal inputs to increase muscle strength and coordination while reducing spontaneous activity. Thus, the inclusion of sEMG assessments in the clinical setting affords important information on how novel therapies may engage and optimize the residual motor command. Nonetheless, current gaps include the lack of studies reporting changes in sEMG properties beyond the amplitude measurement. In order to advance the field, we suggest the incorporation of a broader range of signal properties into the neurophysiological assessment post-SCI and the development of a greater understanding of the relation between these sEMG properties and underlying physiology.

\section{Supplementary Information}

The online version contains supplementary material available at https://doi. org/10.1186/s12984-021-00888-2.

Additional file 1: Figure S1. Additional instrumentation used in all studies (a), studies assessing sEMG properties at volitional effort (b) and rest (c). Table S1. Search strategy.

\section{Acknowledgements}

We would like to acknowledge the direct and indirect support of the Rehabilitation Translational Continuum (ReCon) team, which was supported by the Ontario Spinal Cord Injury Research Network (\#2017-SCI-RECON-1037): Armstrong K, Battaglino R, Cesarz G, Chan BCF, Furlan JC, Cowley KC, Craven BC, Fouad K, Giangregorio L, Habib Perez O, Houston DJ, Magnuson DSK, Masani K, Morse L, Newton E, Park A, Patsakos EM, Petrie S, Ponzano M, and Shepherd J. Only the main authors are responsible for the content of this manuscript.

\section{Authors' contributions}

GB, GL, MJW, and JZ participated in the study design, the study selection process, the data extraction, performed the data analysis, and drafted the manuscript. MP participated in the study selection process and revised the manuscript. JCF and SK revised the manuscript. All authors read and approved the final manuscript.

\section{Funding}

This work was supported by the Wings for Life Spinal Cord Research Foundation (Project \#210)

Availability of data and materials

Not applicable.

\section{Declarations}

Ethics approval and consent to participate

Not applicable.

Consent for publication

Not applicable.

Competing interests

The authors declare that they have no competing interests.

\section{Author details}

${ }^{1}$ KITE-Toronto Rehabilitation Institute, University Health Network, Toronto, ON M5G 2A2, Canada. Institute of Biomedical Engineering, University of Toronto, Toronto, Canada. ${ }^{3}$ Library \& Information Services, Toronto Rehabilitation Institute, University Health Network, Toronto, Canada. ${ }^{4}$ Rehabilitation Sciences Institute, University of Toronto, Toronto, Canada. ${ }^{5}$ Department of Medicine, Division of Physical Medicine and Rehabilitation, University of Toronto, Toronto, Canada. ${ }^{6}$ Division of Physical Medicine and Rehabilitation, Toronto 
Rehabilitation Institute, University Health Network, Toronto, Canada. Institute of Medical Sciences, University of Toronto, Toronto, Canada. ${ }^{8}$ Department of Physical Therapy, University of Toronto, Toronto, Canada. ${ }^{9}$ Edward S. Rogers Sr. Department of Electrical and Computer Engineering, University of Toronto, Toronto, Canada.

Received: 24 February 2021 Accepted: 27 May 2021 Published online: 29 June 2021

\section{References}

1. Shields RK. Muscular, skeletal, and neural adaptations following spinal cord injury. J Orthop Sports Phys Ther. 2002;32(2):65-74.

2. Hayes HB, Chvatal SA, French MA, Ting LH, Trumbower RD. Neuromuscular constraints on muscle coordination during overground walking in persons with chronic incomplete spinal cord injury. Clin Neurophysiol. 2014;125(10):2024-35

3. Dietz V, Muller R. Degradation of neuronal function following a spinal cord injury: mechanisms and countermeasures. Brain. 2004;127(Pt 10):2221-31.

4. Kalsi-Ryan S, Beaton D, Curt A, Duff S, Jiang D, Popovic MR, et al. Defining the role of sensation, strength, and prehension for upper limb function in cervical spinal cord injury. Neurorehabil Neural Repair. 2014;28(1):66-74

5. Furlan JC, Noonan V, Singh A, Fehlings MG. Assessment of impairment in patients with acute traumatic spinal cord injury: a systematic review of the literature. J Neurotrauma. 2011;28(8):1445-77.

6. Furlan JC, Fehlings MG, Tator CH, Davis AM. Motor and sensory assessment of patients in clinical trials for pharmacological therapy of acute spinal cord injury: psychometric properties of the ASIA standards. J Neurotrauma. 2008;25(11):1273-301.

7. Hubli M, Kramer JLK, Jutzeler CR, Rosner J, Furlan JC, Tansey KE, et al Application of electrophysiological measures in spinal cord injury clinical trials: a narrative review. Spinal Cord. 2019;57(11):909-23. https://doi. org/10.1038/s41393-019-0331-z.

8. Sherwood AM. Surface emg. Muscle Nerve. 1996;19:966-79.

9. Calancie B, Molano R, Broton JG, Bean JA, Alexeeva N. Relationship between EMG and muscle force after spinal cord injury. J Spinal Cord Med. 2000;24(1):19-25.

10. Calancie B, Molano MR, Broton JG. EMG for assessing the recovery of voluntary movement after acute spinal cord injury in man. Clin Neurophysiol. 2004;115:1748-59.

11. Calancie B, Del Rosario Molano M, Broton JG, Bean JA, Alexeeva N Relationship between EMG and muscle force after spinal cord injury. J Spinal Cord Med. 2001:24(1):19-25

12. Li K, Atkinson D, Boakye M, Tolfo CZ, Aslan S, Green M, et al. Quantitative and sensitive assessment of neurophysiological status after human spinal cord injury. J Neurosurg Spine. 2012;17(1 Suppl):77-86.

13. Aguiar SA, Baker SN, Gant K, Bohorquez J, Thomas CK. Spasms after spinal cord injury show low-frequency intermuscular coherence. J Neurophysiol. 2018;120(4):1765-71.

14. Heald E, Hart R, Kilgore K, Peckham PH. Characterization of volitional electromyographic signals in the lower extremity after motor complete spinal cord injury. Neurorehabil Neural Repair. 2017;31(6):583-91.

15. Yoo HJ, Lee S, Kim J, Park C, Lee B. Development of 3D-printed myoelectric hand orthosis for patients with spinal cord injury. J Neuroeng Rehabil. 2019;16(1):1-14

16. Alamro RA, Chisholm AE, Williams AMM, Carpenter MG, Lam T. Overground walking with a robotic exoskeleton elicits trunk muscle activity in people with high-thoracic motor-complete spinal cord injury. J Neuroeng Rehabil. 2018;15(1):109.

17. Tricco AC, Lillie E, Zarin W, O'Brien KK, Colquhoun H, Levac D, et al. PRISMA extension for scoping reviews (PRISMA-SCR): checklist and explanation. Ann Intern Med. 2018;169(7):467-73.

18. David G, Mohammadi S, Martin AR, Cohen-Adad J, Weiskopf N, Thompson A, et al. Traumatic and nontraumatic spinal cord injury: pathological insights from neuroimaging. Nat Rev Neurol. 2019;15(12):718-31. https://doi.org/10.1038/s41582-019-0270-5.

19. Melzak J, Stott FD. Electromyographic studies on posture in paraplegics. Proc R Soc Med. 1954;47(12):1113-6.
20. Nesmeyanova TN. Muscular synergy in patients with injuries to the spinal cord. Bull Exp Biol Med. 1974;76(11):1277-81.

21. Nesmeyanova TN. Electromyographic assessment of damage to the injured spinal cord. Bull Exp Biol Med. 1976;80(10):1160-3.

22. Pollock D, Sell H. Myoelectric control sites in the high-level quadriplegic patient. Arch Phys Med Rehabil. 1978;59(5):217-20.

23. Thomas CK, Zaidner EY, Calancie B, Broton JG, Bigland-Ritchie BR. Muscle weakness, paralysis, and atrophy after human cervical spinal cord injury. Exp Neurol. 1997;148(2):414-23.

24. Thomas CK. Contractile properties of human thenar muscles paralyzed by spinal cord injury. Muscle Nerve. 1997;20(7):788-99.

25. Thomas CK, Broton JG, Calancie B. Motor unit forces and recruitment patterns after cervical spinal cord injury. Muscle Nerve. 1997:20(2):212-20.

26. Xiong GX, Zhang JW, Hong Y, Guan Y, Guan H. Motor unit number estimation of the tibialis anterior muscle in spinal cord injury. Spinal Cord. 2008;46(10):696-702.

27. Dietz V, Nakazawa K, Wirz M, Erni T. Level of spinal cord lesion determines locomotor activity in spinal man. Exp Brain Res. 1999:128(3):405-9.

28. Little JW, Powers RK, Michelson P, Moore D, Robinson LR, Goldstein B. Electrodiagnosis of upper limb weakness in acute quadriplegia. Am J Phys Med Rehabil. 1994;73(1):15-22.

29. Lewko JP, Tarkka IM, Dimitrijevic MR. Neurophysiological assessment of the motor and sensory spinal pathways in chronic spinal cord injury. Restor Neurol Neurosci. 1995;7(4):225-34.

30. Calancie B, Del Rosario MM, Broton JG. Neural plasticity as revealed by the natural progression of movement expression-both voluntary and involuntary - in humans after spinal cord injury. Prog Brain Res. 2000;128:71-88

31. Calancie B, Alexeeva N, Broton JG, Suys S, Hall A, Klose KJ. Distribution and latency of muscle responses to transcranial magnetic stimulation of motor cortex after spinal cord injury in humans. J Neurotrauma. 1999;16(1):49-67.

32. Calancie B, Lutton S, Broton JG. Central nervous system plasticity after spinal cord injury in man: interlimb reflexes and the influence of cutaneous stimulation. Electroencephalogr Clin Neurophysiol. 1996;101:304-15.

33. Calancie B, Molano MR, Broton JG. Abductor hallucis for monitoring lower-limb recovery after spinal cord injury in man. Spinal Cord. 2004;42(10):573-80.

34. Dietz V, Wirz M, Colombo G, Curt A. Locomotor capacity and recovery of spinal cord function in paraplegic patients: a clinical and electrophysiological evaluation. Electroencephalogr Clin Neurophysiol. 1998;109(2):140-53.

35. Dietz V, Wirz M, Curt A, Colombo G. Locomotor pattern in paraplegic patients: training effects and recovery of spinal cord function. Spinal Cord. 1998;36(6):380-90.

36. Wirth B, Van Hedel HJ, Curt A. Changes in corticospinal function and ankle motor control during recovery from incomplete spinal cord injury. J Neurotrauma. 2008;25(5):467-78.

37. Mckay WB, Ovechkin AV, Vitaz TW, De PDGLT, Harkema SJ. Neurophysiological characterization of motor recovery in acute spinal cord injury. Spinal Cord. 2011;49:421-9.

38. Sherwood AM, McKay B, Dimitrijević MR. Surface EMG. Muscle Nerve. 1996;19(August):966-79.

39. Sherwood AM, Priebe MM, Graves DE. Consistency of multi-channel surface EMG recordings : application in spinal cord injured subjects. J Electromyogr Kinesiol. 1997;7(2):97-111.

40. Sherwood AM, Dimitrijevic MR, Barry MW. Evidence of subclinical brain influence in clinically complete spinal cord injury: discomplete SCI. J Neurol Sci. 1992;110(1-2):90-8.

41. Sherwood AM, Graves DE, Priebe MM. Altered motor control and spasticity after spinal cord injury: subjective and objective assessment. J Rehabil Res Dev. 2000;37(1):41-52.

42. Lee DC, Lim HK, Mckay WB, Priebe MM, Holmes SA, Sherwood AM. Toward an objective interpretation of surface EMG patterns : a voluntary response index (VRI). J Electromyogr Kinesiol. 2004;14:379-88.

43. Zoghi M, Galea M, Morgan D. Brain motor control assessment of upper limb function in patients with spinal cord injury. J Spinal Cord Med. 2016:39(2):162-74. 
44. Gomez-Soriano J, Castellote JM, Perez-Rizo E, Esclarin A, Taylor JS. Voluntary ankle flexor activity and adaptive coactivation gain is decreased by spasticity during subacute spinal cord injury. Exp Neurol. 2010;224(2):507-16

45. Moss CW, Kilgore KL, Peckham PH. A novel command signal for motor neuroprosthetic control. Neurorehabil Neural Repair. 2011;25(9):847-54.

46. Labruyère R, Zimmerli M, Van Hedel HJ. Slowed down: response time deficits in well-recovered subjects with incomplete spinal cord injury. Arch Phys Med Rehabil. 2013;94(10):2020-6.

47. Squair JW, Bjerkefors A, Inglis JT, Lam T, Carpenter MG. Cortical and vestibular stimulation reveal preserved descending motor pathways in individuals with motorcomplete spinal cord injury. J Rehabil Med. 2016:48(7):589-96.

48. Chou S, Pei Y, Lai C, Kuo C, Fu T, Hong W. Motor Control in Patients with Incomplete Spinal Cord Injuries and Various Voluntary Movement Capabilities. Chang Gung Med J. 2005;28(5):349-56.

49. Bjerkefors A, Squair JW, Chua R, Lam T, Chen Z, Carpenter MG. Assessment of abdominal muscle function in individuals with motor-complete spinal cord injury above T6 in response to transcranial magnetic stimulation. J Rehabil Med. 2015;47(2):138-46.

50. Bjerkefors A, Squair JW, Malik R, Lam T, Chen Z, Carpenter MG. Diagnostic accuracy of common clinical tests for assessing abdominal muscle function after motor-complete spinal cord injury above T6. Spinal Cord. 2015;53(2):114-9.

51. Foldes ST, Weber DJ, Collinger JL. Altered modulation of sensorimotor rhythms with chronic paralysis. J Neurophysiol. 2017;118(4):2412-20.

52. Hyun KL, Lee DC, McKay WB, Protas EJ, Holmes SA, Priebe MM, et al. Analysis of sEMG during voluntary movement-Part II: Voluntary response index sensitivity. IEEE Trans Neural Syst Rehabil Eng. 2004;12(4):416-21.

53. McKay WB, Lee DC, Lim HK, Holmes SA, Sherwood AM. Neurophysiological examination of the corticospinal system and voluntary motor control in motor-incomplete human spinal cord injury. Exp Brain Res. 2005;163(3):379-87

54. Lim HK, Lee DC, Mckay WB, Priebe MM, Holmes SA, Sherwood AM. Original Article Neurophysiological assessment of lower-limb voluntary control in incomplete spinal cord injury. Spinal Cord. 2005;43:283-90.

55. Lim HK, Sherwood AM. Reliability of surface electromyographic measurements from subjects with spinal cord injury during voluntary motor tasks. J Rehabil Res Dev. 2005;42(4):413. http://www.rehab.research.va. gov/jour/05/42/4/lim.html

56. Ovechkin AV, Vitaz TW, Terson de Paleville DGL, McKay WB. Quality of residual neuromuscular control and functional deficits in patients with spinal cord injury. Front Neurol. 2013. https://doi.org/10.3389/fneur. 2013.00174

57. Kim HE, Thompson CK, Hornby TG. Muscle activation varies with contraction mode in human spinal cord injury. Muscle Nerve. 2015;51(2):235-45.

58. Kim HE, Corcos DM, George Hornby T. Increased spinal reflex excitability is associated with enhanced central activation during voluntary lengthening contractions in human spinal cord injury. J Neurophysiol. 2015;114(1):427-39.

59. Prak RF, Doestzada M, Thomas CK, Tepper M, Zijdewind I. Reduced voluntary drive during sustained but not during brief maximal voluntary contractions in the first dorsal interosseous weakened by spinal cord injury. J Appl Physiol. 2015;119(11):1320-9.

60. Jordanic M, Rojas-Martinez M, Mananas MA, Alonso JF. Spatial distribution of HD-EMG improves identification of task and force in patients with incomplete spinal cord injury. J Neuroeng Rehabil. 2016;13 (1) (no(41 PG-). http://www.jneuroengrehab.com/home/NS-.

61. Jordanic M, Rojas-Martinez M, Mananas MA, Alonso JF. Prediction of isometric motor tasks and effort levels based on high-density EMG in patients with incomplete spinal cord injury. J Neural Eng. 2016;13(4):46002.

62. Gant K, Bohorquez J, Thomas CK. Long-term recording of electromyographic activity from multiple muscles to monitor physical activity of participants with or without a neurological disorder. Biomed Tech. 2019;64(1):81-91.

63. Dekker B, Verschuren O, Balemans ACJ, Baart N, Tubbing F, van Koppenhagen $C F$, et al. Energy expenditure and muscle activity during lying, sitting, standing, and walking in people with motor-incomplete spinal cord injury. Spinal Cord. 2018;56(10):1008-16.

64. Wierzbicka MM, Wiegner AW. Effects of weak antagonist on fast elbow flexion movements in man. Exp Brain Res. 1992;91(3):509-19.

65. Wierzbicka MM, Wiegner AW. Accuracy of motor responses in subjects with and without control of antagonist muscle. J Neurophysiol. 1996;75(6):2533-41

66. Alexeeva N, Broton JG, Suys S, Calancie B. Central cord syndrome of cervical spinal cord injury: widespread changes in muscle recruitment studied by voluntary contractions and transcranial magnetic stimulation. Exp Neurol. 1997;148(2):399-406.

67. Thomas CK, Tucker ME, Bigland-Ritchie B. Voluntary muscle weakness and co-activation after chronic cervical spinal cord injury. J Neurotrauma. 1998;15(2):149-61.

68. Marciello MA, Herbison GJ, Cohen ME, Schmidt R. Elbow extension using anterior deltoids and upper pectorals in spinal cord-injured subjects. Arch Phys Med Rehabil. 1995;76(5):426-32.

69. Prilutsky B, Ashley D, Vanhiel L, Harley L, Tidwell J, Backus D. Motor control and motor redundancy in the upper extremity: Implications for neurorehabilitation. Top Spinal Cord Inj Rehabil. 2011;17(1):7-15.

70. Tang SF, Tuel SM, McKay WB, Dimitrijevic MR. Correlation of motor control in the supine position and assistive device used for ambulation in chronic incomplete spinal cord-injured persons. Am J Phys Med Rehabil. 1994;73(4):268-74.

71. Seelen HAM, Vuurman EF. Compensatory muscle activity for sitting posture during upper extremity task performance in paraplegic persons. Scand J Rehab Med. 1991;23:89-96.

72. Seelen HA, Potten YJ, Drukker J, Reulen JP, Pons C. Development of new muscle synergies in postural control in spinal cord injured subjects. J Electromyogr Kinesiol. 1998;8(1):23-34.

73. Huang HJ, Ferris DP. Upper limb effort does not increase maximal voluntary muscle activation in individuals with incomplete spinal cord injury. Clin Neurophysiol. 2009;120(9):1741-9.

74. Dietz V, Muller R, Colombo G. Locomotor activity in spinal man: significance of afferent input from joint and load receptors. Brain. 2002;125(Pt 12):2626-34.

75. Knikou M, Angeli CA, Ferreira CK, Harkema SJ. Soleus H-reflex modulation during body weight support treadmill walking in spinal cord intact and injured subjects. Exp Brain Res. 2009;193(3):397-407.

76. van Hedel HJ, Wirth B, Dietz V. Limits of locomotor ability in subjects with a spinal cord injury. Spinal Cord. 2005;43(10):593-603.

77. Wang P, Low KH, McGregor AH, Tow A. Detection of abnormal muscle activations during walking following spinal cord injury (SCI). Res Dev Disabil. 2013;34(4):1226-35.

78. Lam T, Wirz M, Lunenburger L, Dietz V. Swing phase resistance enhances flexor muscle activity during treadmill locomotion in incomplete spinal cord injury. Neurorehabil Neural Repair. 2008;22(5):438-46.

79. Kawashima N, Nakazawa K, Akai M. Characteristics of the locomotor-like muscle activity during orthotic gait in paraplegic persons. Neurol Res. 2008;30(1):36-45.

80. Gordon KE, Wu M, Kahn JH, Schmit BD. Feedback and feedforward locomotor adaptations to ankle-foot load in people with incomplete spinal cord injury. J Neurophysiol. 2010;104(3):1325-38. http://jn.physi ology.org/cgi/reprint/104/3/1325NS-.

81. Houldin A, Luttin K, Lam T. Locomotor adaptations and aftereffects to resistance during walking in individuals with spinal cord injury. J Neurophysiol. 2011;106(1):247-58.

82. Pepin A, Norman KE, Barbeau H. Treadmill walking in incomplete spinalcord-injured subjects: 1. Adaptation to changes in speed. Spinal Cord. 2003;41(5):257-70

83. Lunenburger L, Bolliger M, Czell D, Muller R, Dietz V. Modulation of locomotor activity in complete spinal cord injury. Exp Brain Res. 2006;174(4):638-46.

84. Forrest GF, Sisto SA, Asselin P, Mores J, Bond Q, LaFountaine MF, et al. Locomotor training with incremental changes in velocity: muscle and metabolic responses. Top Spinal Cord Inj Rehabil. 2008;14(1):16-22.

85. Leroux A, Fung J, Barbeau H. Adaptation of the walking pattern to uphill walking in normal and spinal-cord injured subjects. Exp Brain Res. 1999;126(3):359-68. 
86. Dietz V, Grillner S, Trepp A, Hubli M, Bolliger M. Changes in spinal reflex and locomotor activity after a complete spinal cord injury: a common mechanism? Brain. 2009;132(Pt 8):2196-205.

87. Hubli M, Dietz V, Bolliger M. Influence of spinal reflexes on the locomotor pattern after spinal cord injury. Gait Posture. 2011;34(3):409-14.

88. Muller R, Dietz V. Neuronal function in chronic spinal cord injury: divergence between locomotor and flexion- and H-reflex activity. Clin Neurophysiol. 2006;117(7):1499-507.

89. Field-Fote EC, Dietz V. Single joint perturbation during gait: preserved compensatory response pattern in spinal cord injured subjects. Clin Neurophysiol. 2007;118(7):1607-16.

90. Knikou M, Angeli CA, Ferreira CK, Harkema SJ. Flexion reflex modulation during stepping in human spinal cord injury. Exp Brain Res. 2009;196(3):341-51.

91. Cotey D, George Hornby T, Gordon KE, Schmit BD. Increases in muscle activity produced by vibration of the thigh muscles during locomotion in chronic human spinal cord injury. Exp Brain Res. 2009;196(3):361-74.

92. Oates AR, Arora T, Lanovaz JL, Musselman KE. The effects of light touch on gait and dynamic balance during normal and tandem walking in individuals with an incomplete spinal cord injury. Spinal Cord. 2020. https://doi.org/10.1038/s41393-020-0516-5.

93. Dobkin $\mathrm{BH}$, Harkema S, Requejo P, Edgerton VR. Modulation of locomotor-like EMG activity in subjects with complete and incomplete spinal cord injury. J Neurol Rehabil. 1995;9(4):183-90.

94. Harkema SJ, Hurley SL, Patel UK, Requejo PS, Dobkin BH, Edgerton VR. Human lumbosacral spinal cord interprets loading during stepping. J Neurophysiol. 1997;77(2):797-811.

95. Maegele M, Muller S, Wernig A, Edgerton VR, Harkema SJ. Recruitment of spinal motor pools during voluntary movements versus stepping after human spinal cord injury. J Neurotrauma. 2002;19(10):1217-29.

96. Kawashima N, Nozaki D, Abe MO, Akai M, Nakazawa K. Alternate leg movement amplifies locomotor-like muscle activity in spinal cord injured persons. J Neurophysiol. 2005;93(2):777-85.

97. Ferris DP, Gordon KE, Beres-Jones JA, Harkema SJ. Muscle activation during unilateral stepping occurs in the nonstepping limb of humans with clinically complete spinal cord injury. Spinal Cord. 2004;42(1):14-23.

98. Kawashima N, Nozaki D, Abe MO, Nakazawa K. Shaping appropriate locomotive motor output through interlimb neural pathway within spinal cord in humans. J Neurophysiol. 2008;99(6):2946-55.

99. Corbett EA, Sachs NA, Kording KP, Perreault EJ. Multimodal decoding and congruent sensory information enhance reaching performance in subjects with cervical spinal cord injury. Front Neurosci. 2014:8:123.

100. Potten YJ, Seelen HA, Drukker J, Reulen JP, Drost MR. Postural muscle responses in the spinal cord injured persons during forward reaching. Ergonomics. 1999;42(9):1200-15.

101. Magnani PE, Marques NR, Junior AC, de Abreu DC. Adapted sport effect on postural control after spinal cord injury. Spinal Cord. 2016;54(12):1188-96.

102. Koshland GF, Galloway JC, Farley B. Novel muscle patterns for reaching after cervical spinal cord injury: a case for motor redundancy. Exp Brain Res. 2005;164(2):133-47.

103. Zariffa J, Steeves J, Pai DK. Changes in hand muscle synergies in subjects with spinal cord injury: characterization and functional implications. J Spinal Cord Med. 2012;35(5):310-8.

104. Stahl VA, Hayes HB, Buetefisch CM, Wolf SL, Trumbower RD. Modulation of hand aperture during reaching in persons with incomplete cervical spinal cord injury. Exp Brain Res. 2015;233(3):871-84.

105. Calabro FJ, Perez MA. Bilateral reach-to-grasp movement asymmetries after human spinal cord injury. J Neurophysiol. 2016;115(1):157-67.

106. Lei $Y$, Perez MA. Phase-dependent deficits during reach-to-grasp after human spinal cord injury. J Neurophysiol. 2018;119(1):251-61.

107. Britten L, Coats RO, Ichiyama RM, Raza W, Jamil F, Astill SL. The effect of task symmetry on bimanual reach-to-grasp movements after cervical spinal cord injury. Exp Brain Res. 2018;236(11):3101-11.

108. Seelen HA, Vuurman EF. Compensatory muscle activity for sitting posture during upper extremity task performance in paraplegic persons. Scand J Rehabil Med. 1991;23(2):89-96.

109. Seelen HAM, Potten YJM, Huson A, Spaans F, Reulen JPH. Impaired balance control in paraplegics subjects. J Electromyogr Kinesiol. 1997;7(2):149-60.
110. Thigpen MT, Cauraugh J, Creel G, Day K, Flynn S, Fritz S, et al. Adaptation of postural responses during different standing perturbation conditions in individuals with incomplete spinal cord injury. Gait Posture. 2009;29(1):113-8

111. Arora T, Musselman KE, Lanovaz JL, Linassi G, Arnold C, Milosavljevic $\mathrm{S}$, et al. Reactive balance responses to an unexpected slip perturbation in individuals with incomplete spinal cord injury. Clin Biomech. 2020;78(January 2019):105099. https://doi.org/10.1016/j.clinbiomech. 2020.105099.

112. Fok KL, Lee JW, Unger J, Chan K, Nozaki D, Musselman KE, et al. Cosine tuning determines plantarflexors' activities during human upright standing and is affected by incomplete spinal cord injury. J Neurophysiol. 2020;123(6):2343-54.

113. Perez-Nombela S, Barroso F, Torricelli D, de Los Reyes-Guzman A, Del-Ama AJ, Gomez-Soriano J, et al. Modular control of gait after incomplete spinal cord injury: differences between sides. Spinal Cord. 2017;55(1):79-86

114. Baniasad M, Farahmand F, Arazpour M, Zohoor H. Coordinated activities of trunk and upper extremity muscles during walker-assisted paraplegic gait: a synergy study. Hum Mov Sci. 2018:62:184-93.

115. Barroso FO, Torricelli D, Bravo-Esteban E, Taylor J, Gomez-Soriano J, Santos C, et al. Muscle synergies in cycling after incomplete spinal cord injury: correlation with clinical measures of motor function and spasticity. Front Hum Neurosci. 2016;9(JAN2016):706. https://doi.org/10.3389/ fnhum.2015.00706.

116. Tkach D, Huang H, Kuiken TA. Study of stability of time-domain features for electromyographic pattern recognition. J Neuroeng Rehabil. 2010;7(21):1-13.

117. Hudgins B, Parker P, Scott RN. A new atrategy for multifunction myoelectric control. IEEE Trans Biomed Eng. 1993;40(1):82-94.

118. Umezu Y, Shiba N, Tajima F, Mizushima T, Okawa H, Ogata H, et al. Muscle endurance and power spectrum of the triceps brachii in wheelchair marathon racers with paraplegia. Spinal Cord. 2003;41(9):511-5.

119. Niemeyer LO, Aronow HU, Kasman GS. A pilot study to investigate shoulder muscle fatigue during a sustained isometric wheelchairpropulsion effort using surface EMG. Am J Occup Ther. 2004;58:587-93.

120. Uzun S, Pourmoghaddam A, Hieronymus M, Thrasher TA. Evaluation of muscle fatigue of wheelchair basketball players with spinal cord injury using recurrence quantification analysis of surface EMG. Eur J Appl Physiol. 2012;112(11):3847-57.

121. Bravo-Esteban E, Taylor J, Aleixandre M, Simon-Martínez C, Torricelli D, Pons JL, et al. Tibialis anterior muscle coherence during controlled voluntary activation in patients with spinal cord injury: diagnostic potential for muscle strength, gait and spasticity. J Neuroeng Rehabil. 2014;11:23.

122. Bravo-Esteban E, Taylor J, Aleixandre M, Simon-Martinez C, Torricelli D, Pons JL, et al. Longitudinal estimation of intramuscular Tibialis Anterior coherence during subacute spinal cord injury: relationship with neurophysiological, functional and clinical outcome measures. J Neuroeng Rehabil. 2017;14(1):58

123. Cremoux S, Tallet J, Dal Maso F, Berton E, Amarantini D. Impaired corticomuscular coherence during isometric elbow flexion contractions in humans with cervical spinal cord injury. Eur J Neurosci. 2017:46(4):1991-2000.

124. Liu J, Li X, Li G, Zhou P. EMG feature assessment for myoelectric pattern recognition and channel selection: a study with incomplete spinal cord injury. Med Eng Phys. 2014;36(7):975-80. https://doi.org/10.1016/j. medengphy.2014.04.003.

125. Liu J, Zhou P. A novel myoelectric pattern recognition strategy for hand function restoration after incomplete cervical spinal cord injury. IEEE Trans Neural Syst Rehabil Eng. 2013;21(1):96-103.

126. Lu Z, Stampas A, Francisco GE, Zhou P. Offline and online myoelectric pattern recognition analysis and real-time control of a robotic hand after spinal cord injury. J Neural Eng. 2019;16(3):036018.

127. Liu J, Liu Q. Use of the integrated profile for voluntary muscle activity detection using EMG signals with spurious background spikes: a study with incomplete spinal cord injury. Biomed Signal Process Control. 2016;24:19-24. https://doi.org/10.1016/j.bspc.2015.09.004.

128. Liu J, Ying D, Zhou P. Wiener filtering of surface EMG with a priori SNR estimation toward myoelectric control for neurological injury patients. Med Eng Phys. 2014;36(12):1711-5. 
129. Liu J, Ying D, Zev Rymer W, Zhou P. Subspace based adaptive denoising of surface EMG from neurological injury patients. J Neural Eng. 2014;11(5):56025.

130. Zijdewind I, Thomas CK. Motor unit firing during and after voluntary contractions of human thenar muscles weakened by spinal cord injury. J Neurophysiol. 2003;89(4):2065-71.

131. Zijdewind I, Gant K, Bakels R, Thomas CK. Do additional inputs change maximal voluntary motor unit firing rates after spinal cord injury? Neurorehabil Neural Repair. 2012;26(1):58-67.

132. Winslow J, Dididze M, Thomas CK. Automatic classification of motor unit potentials in surface EMG recorded from thenar muscles paralyzed by spinal cord injury. J Neurosci Methods. 2009;185(1):165-77.

133. Gorassini MA, Norton JA, Nevett-Duchcherer J, Roy FD, Yang JF. Changes in locomotor muscle activity after treadmill training in subjects with incomplete spinal cord injury. J Neurophysiol. 2009;101(2):969-79.

134. Meyer C, Filli L, Stalder SA, Awai Easthope C, Killeen T, von Tscharner $V$, et al. Targeted walking in incomplete spinal cord injury: role of corticospinal control. J Neurotrauma. 2020;13:1-13.

135. Norton JA, Gorassini MA. Changes in cortically related intermuscular coherence accompanying improvements in locomotor skills in incomplete spinal cord injury. J Neurophysiol. 2006;95(4):2580-9.

136. Hansen NL, Conway BA, Halliday DM, Hansen S, Pyndt HS, BieringSørensen F, et al. Reduction of common synaptic drive to ankle dorsiflexor motoneurons during walking in patients with spinal cord lesion. J Neurophysiol. 2005;94(2):934-42.

137. Barthelemy D, Willerslev-Olsen M, Lundell H, Conway BA, Knudsen $H$, Biering-Sorensen $\mathrm{F}$, et al. Impaired transmission in the corticospinal tract and gait disability in spinal cord injured persons. J Neurophysiol. 2010;104(2):1167-76.

138. Bravo-Esteban E, Taylor J, Aleixandre M, Simón-Martínez C, Torricelli $D$, Pons $J$, et al. Longitudinal estimation of intramuscular Tibialis Anterior coherence during subacute spinal cord injury: relationship with neurophysiological, functional and clinical outcome measures. J Neuroeng Rehabil. 2017;14(1):1-11.

139. McKay WB, Ovechkin AV, Vitaz TW, Terson de Paleville DG, Harkema SJ. Long-lasting involuntary motor activity after spinal cord injury. Spinal Cord. 2011;49(1):87-93

140. Douglas AJ, Walsh EG, Wright GW, Edmond P. Muscle tone around the human knee in paraplegia. Q J Exp Physiol. 1989;74(6):897-905.

141. Bajd T, Vodovnik L. Pendulum testing of spasticity. J Biomed Eng. 1984;6(1):9-16

142. Bajd T, Bowman B. Testing and modelling of spasticity. J Biomed Eng. 1982;4(2):90-6.

143. Cioni B, Dimitrijevic MR, McKay WB, Sherwood AM. Voluntary supraspinal suppression of spinal reflex activity in paralyzed muscles of spinal cord injury patients. Exp Neurol. 1986;93(3):574-83.

144. Gildenberg PL, Campos RJ, Dimitrijevic MR. Characteristics of the tonic stretch reflex in spastic spinal cord and head-injured patients. Appl Neurophysiol. 1985;48(1-6):106-10.

145. Calancie B, Lutton S, Broton JG. Central nervous system plasticity after spinal cord injury in man: interlimb reflexes and the influence of cutaneous stimulation. Electroencephalogr Clin Neurophysiol. 1996;101(4):304-15.

146. Onushko T, Schmit BD, Li K, Atkinson D, Boakye M, Tolfo CZ, et al. Coordinated muscle activity of the legs during assisted bilateral hip oscillation in human spinal cord injury. Biomed Sci Instrum. 2008:44:286-91.

147. Onushko T, Hyngstrom A, Schmit BD. Effects of multijoint spastic reflexes of the legs during assisted bilateral hip oscillations in human spinal cord injury. Arch Phys Med Rehabil. 2010;91(8):1225-35. https:// doi.org/10.1016/j.apmr.2010.04.014.

148. Wallace DM, Ross BH, Thomas CK. Characteristics of lower extremity clonus after human cervical spinal cord injury. J Neurotrauma. 2012;29(5):915-24.

149. Wu M, Kahn JH, Hornby TG, Schmit BD. Rebound responses to prolonged flexor reflex stimuli in human spinal cord injury. Exp Brain Res. 2009;193(2):225-37

150. Hornby TG, Kahn JH, Wu M, Schmit BD. Temporal facilitation of spastic stretch reflexes following human spinal cord injury. J Physiol. 2006:571(Pt 3):593-604
151. Sköld C, Harms-Ringdahl K, Seiger Å. Movement-provoked muscle torque and EMG activity in longstanding motor complete spinal cord injured individuals. J Rehabil Med. 2002;34(2):86-90.

152. Onushko T, Schmit BD. Reflex response to imposed bilateral hip oscillations in human spinal cord injury. J Neurophysiol. 2007;98(4):1849-61.

153. Wu M, Hornby TG, Hilb J, Schmit BD. Extensor spasms triggered by imposed knee extension in chronic human spinal cord injury. Exp Brain Res. 2005;162(2):239-49.

154. Wu M, Schmit BD. Spastic reflexes triggered by ankle load release in human spinal cord injury. J Neurophysiol. 2006;96(6):2941-50.

155. Kim Y, Youm Y, Wu M, Schmit BD. Modulation of flexor reflexes by static and dynamic hip proprioceptors in chronic human spinal cord injury. J Clin Neurosci. 2007;14(11):1078-88.

156. Field-Fote $E$, Ness LL, Ionno M. Vibration elicits involuntary, step-like behavior in individuals with spinal cord injury. Neurorehabil Neural Repair. 2012;26(7):861-9.

157. Schmit BD, Benz EN. Extensor reflexes in human spinal cord injury: activation by hip proprioceptors. Exp Brain Res. 2002;145(4):520-7.

158. Beres-Jones JA, Johnson TD, Harkema SJ. Clonus after human spinal cord injury cannot be attributed solely to recurrent muscle-tendon stretch. Exp Brain Res. 2003;149(2):222-36.

159. Calancie B. Spinal myoclonus after spinal cord injury. J Spinal Cord Med. 2006;29(4):413-24

160. Steldt RE, Schmit BD. Modulation of coordinated muscle activity during imposed sinusoidal hip movements in human spinal cord injury. J Neurophysiol. 2004;92(2):673-85.

161. Wu M, Schmit BD. Reflex responses to combined hip and knee motion in human chronic spinal cord injury. J Rehabil Res Dev. 2010:47(2):117-32

162. Onushko T, Hyngstrom A, Schmit BD. Bilateral oscillatory hip movements induce windup of multijoint lower extremity spastic reflexes in chronic spinal cord injury. J Neurophysiol. 2011;106(4):1652-61.

163. Zijdewind I, Bakels R, Thomas CK. Motor unit firing rates during spasms in thenar muscles of spinal cord injured subjects. Front Hum Neurosci. 2014;8:922.

164. Thomas CK, Dididze M, Martinez A, Morris RW. Identification and classification of involuntary leg muscle contractions in electromyographic records from individuals with spinal cord injury. J Electromyogr Kinesiol. 2014;24(5):747-54.

165. Winslow J, Martinez A, Thomas CK. Automatic identification and classification of muscle spasms in long-term EMG recordings. IEEE J Biomed Health Inform. 2015:19(2):464-70.

166. Mummidisetty CK, Bohorquez J, Thomas CK. Automatic analysis of EMG during clonus. J Neurosci Methods. 2012;204(1):35-43.

167. Skold C, Harms-Ringdahl K, Hulting C, Levi R, Seiger A. Simultaneous Ashworth measurements and electromyographic recordings in tetraplegic patients. Arch Phys Med Rehabil. 1998;79(8):959-65.

168. Zupan B, Stokic DS, Bohanec M, Priebe MM, Sherwood AM. Relating clinical and neurophysiological assessment of spasticity by machine learning. Int J Med Inform. 1998;49(2):243-51.

169. Benz EN, Hornby TG, Bode RK, Scheidt RA, Schmit BD. A physiologically based clinical measure for spastic reflexes in spinal cord injury. Arch Phys Med Rehabil. 2005;86(1):52-9.

170. van der Salm A, Veltink PH, Hermens HJ, ljzerman MJ, Nene AV. Development of a new method for objective assessment of spasticity using full range passive movements. Arch Phys Med Rehabil. 2005;86(10):1991-7.

171. Woolacott AJ, Burne JA. The tonic stretch reflex and spastic hypertonia after spinal cord injury. Exp Brain Res. 2006:174(2):386-96.

172. Voerman GE, Fleuren JF, Kallenberg LA, Rietman JS, Snoek GJ, Hermens HJ. Patient ratings of spasticity during daily activities are only marginally associated with long-term surface electromyography. J Neurol Neurosurg Psychiatry. 2009;80(2):175-81.

173. Grippo A, Carrai R, Hawamdeh Z, Falsini C, Aito S, Pinto F, et al. Biomechanical and electromyographic assessment of spastic hypertonus in motor complete traumatic spinal cord-injured individuals. Spinal Cord. 2011:49(1):142-8

174. Tibbett J, Widerstrom-Noga EG, Thomas CK, Field-Fote EC. Impact of spasticity on transfers and activities of daily living in individuals with spinal cord injury. J Spinal Cord Med. 2019;42(3):318-27.

175. Mayo M, DeForest BA, Castellanos M, Thomas CK. Characterization of involuntary contractions after spinal cord injury reveals associations 
between physiological and self-reported measures of spasticity. Front Integr Neurosci. 2017;11(February):1-15.

176. Magnusson SP, Simonsen EB, Dyhre-Poulsen P, Aagaard P, Mohr T, Kjaer M. Viscoelastic stress relaxation during static stretch in human skeletal muscle in the absence of EMG activity. Scand J Med Sci Sports. 1996;6(6):323-8.

177. Li X, Jahanmiri-Nezhad F, Rymer WZ, Zhou P. An Examination of the Motor Unit Number Index (MUNIX) in muscles paralyzed by spinal cord injury. IEEE Trans Inf Technol Biomed. 2012:16(6):1143-9.

178. Li L, Li X, Liu J, Zhou P. Alterations in multidimensional motor unit number index of hand muscles after incomplete cervical spinal cord injury. Front Hum Neurosci. 2015;9:238.

179. Yang JF, Stein RB, Jhamandas J, Gordon T. Motor unit numbers and contractile properties after spinal cord injury. Ann Neurol. 1990;28(4):496-502

180. Witt A, Fuglsang-Frederiksen A, Finnerup NB, Kasch H, Tankisi H. Detecting peripheral motor nervous system involvement in chronic spinal cord injury using two novel methods: MScanFit MUNE and muscle velocity recovery cycles. Clin Neurophysiol. 2020;131(10):2383-92. https://doi.org/10.1016/..clinph.2020.06.032.

181. Zijdewind I, Thomas CK. Spontaneous motor unit behavior in human thenar muscles after spinal cord injury. Muscle Nerve. 2001;24(7):952-62.

182. Wallace DM, Ross BH, Thomas CK. Motor unit behavior during clonus. J Appl Physiol. 2005;99(6):2166-72.

183. Zijdewind I, Thomas CK. Firing patterns of spontaneously active motor units in spinal cord-injured subjects. J Physiol. 2012;590(7):1683-97.

184. Korupolu R, Stampas A, Singh M, Zhou P, Francisco G. Electrophysiological outcome measures in spinal cord injury clinical trials: a systematic review. Top Spinal Cord Inj Rehabil. 2019;25(4):340-54.

185. Del Vecchio A, Holobar A, Falla D, Felici F, Enoka RM, Farina D. Tutorial: Analysis of motor unit discharge characteristics from high-density surface EMG signals. J Electromyogr Kinesiol. 2020;53:102426. https:// doi.org/10.1016/j.jelekin.2020.102426.

186. Nawab SH, Chang S-S, De Luca CJ. High-yield decomposition of surface EMG signals. Clin Neurophysiol. 2010;121(10):1602-15.

187. Roberson DJ, Longbotham HG, Schrader CB. Robust detection of below-lesion, non-invasive electromyographic signals. Biomed Sci Instrum. 1993;29:169-76.

188. Pilkar R, Momeni K, Ramanujam A, Ravi M, Garbarini E, Forrest GF. Use of Surface EMG in Clinical Rehabilitation of Individuals With SCI: Barriers and Future Considerations. Front Neurol. 2020;11 (January 2021):578559.

189. Merletti R, Disselhorst-klug C, Rymer WZ, Campanini I. Surface electromyography: barriers limiting widespread use of SEMG in clinical assessment and neurorehabilitation. Front Neurol. 2021;12:642257.

190. Mandeville RM, Brown JM, Sheean GL. A neurophysiological approach to nerve transfer to restore upper limb function in cervical spinal cord injury. Neurosurg Focus. 2017;43(1):1-9.
191. Zhang X, Li X, Tang X, Chen X, Chen X, Zhou P. Spatial filtering for enhanced high-density surface electromyographic examination of neuromuscular changes and its application to spinal cord injury. J Neuroeng Rehabil. 2020;17(1):1-14. https://doi.org/10.1186/ s12984-020-00786-z.

192. Ahuja CS, Wilson JR, Nori S, Kotter MRN, Druschel C, Curt A, et al. Traumatic spinal cord injury. Nat Rev Dis Primers. 2017;3:1-21.

193. Rosenzweig ES, Courtine G, Jindrich DL, Brock JH, Ferguson AR, Strand SC, et al. Extensive spontaneous plasticity of corticospinal projections after primate spinal cord injury. Nat Neurosci. 2010;13(12):1505-12.

194. De Luca CJ, Adam A, Wotiz R, Gilmore LD, Nawab SH. Decomposition of surface EMG signals. J Neurophysiol. 2006;96(3):1646-57.

195. De Luca CJ, Chang SS, Roy SH, Kline JC, Hamid NS. Decomposition of surface EMG signals from cyclic dynamic contractions. J Neurophysiol. 2015;113(6):1941-51.

196. Chen M, Holobar A, Zhang X, Zhou P. Progressive FastICA peel-off and convolution kernel compensation demonstrate high agreement for high density surface EMG decomposition. Neural Plast. 2016. https:// doi.org/10.1155/2016/3489540.

197. Chen M, Zhou P. A novel framework based on FastlCA for high density surface EMG decomposition. IEEE Trans Neural Syst Rehabil Eng. 2016;24(1):117-27.

198. Chen M, Zhang X, Chen X, Zhou P. Automatic implementation of progressive FastICA Peel-Off for high density surface EMG decomposition. IEEE Trans Neural Syst Rehabil Eng. 2018;26(1):144-52.

199. Holobar A, Zazula D. Multichannel blind source separation using convolution Kernel compensation. IEEE Trans Signal Process. 2007;55(9):4487-96.

200. Holobar A, Farina D, Gazzoni M, Merletti R, Zazula D. Estimating motor unit discharge patterns from high-density surface electromyogram. Clin Neurophysiol. 2009;120(3):551-62. https://doi.org/10.1016/j.clinph. 2008.10.160.

201. Glaser V, Holobar A, Zazula D. Real-time motor unit identification from high-density surface EMG. IEEE Trans Neural Syst Rehabil Eng. 2013;21(6):949-58.

202. Ting JE, Vecchio A Del, Sarma D, Colachis SC, Annetta NV, Collinger JL, et al. Sensing and decoding the neural drive to paralyzed muscles during attempted movements of a person with tetraplegia using a sleeve array. medRxiv. 2021;2021.02.24.21250962. https://doi.org/10.1101/ 2021.02.24.21250962

\section{Publisher's Note}

Springer Nature remains neutral with regard to jurisdictional claims in published maps and institutional affiliations.

Ready to submit your research? Choose BMC and benefit from:

- fast, convenient online submission

- thorough peer review by experienced researchers in your field

- rapid publication on acceptance

- support for research data, including large and complex data types

- gold Open Access which fosters wider collaboration and increased citations

- maximum visibility for your research: over $100 \mathrm{M}$ website views per year

At BMC, research is always in progress.

Learn more biomedcentral.com/submissions 